\title{
Root Exudates of Stressed Plants Stimulate and Attract Trichoderma Soil Fungi
}

\author{
Nadia Lombardi, ${ }^{1,2}$ Stefania Vitale, ${ }^{3}$ David Turrà, ${ }^{3}$ Massimo Reverberi, ${ }^{4}$ Corrado Fanelli, ${ }^{4}$ \\ Francesco Vinale, ${ }^{1}$ Roberta Marra, ${ }^{2}$ Michelina Ruocco, ${ }^{1}$ Alberto Pascale, ${ }^{2}$ Giada d'Errico, ${ }^{1}$ \\ Sheridan L. Woo, ${ }^{1,5}$ and Matteo Lorito ${ }^{1,2,+}$ \\ ${ }^{1}$ Istituto per la Protezione Sostenibile delle Piante, Consiglio Nazionale delle Ricerche; ${ }^{2}$ Dipartimento di Agraria, Università degli \\ Studi di Napoli Federico II, 80055 Portici (NA), Italy; ${ }^{3}$ Departamento de Genetica, Facultad de Ciencias, Campus Rabanales \\ 14071 Córdoba, Spain; ${ }^{4}$ Dipartimento di Biologia Ambientale, Università la Sapienza, 00185 Roma, Italy; and ${ }^{5}$ Dipartimento di \\ Farmacia, Università degli Studi di Napoli Federico II, 80131 Napoli, Italy
}

Accepted 14 March 2018.

\begin{abstract}
Plant roots release complex mixtures of bioactive molecules, including compounds that affect the activity and modify the composition of the rhizosphere microbiome. In this work, we investigated the initial phase of the interaction between tomato and an effective biocontrol strain of Trichoderma harzianum (T22). We found that root exudates (RE), obtained from plants grown in a split-root system and exposed to various biotic and abiotic stress factors (wounding, salt, pathogen attack), were able to stimulate the growth and act as chemoattractants of the biocontrol fungus. On the other hand, some of the treatments did not result in an enhanced chemotropism on Fusarium oxysporum f. sp. lycopersici, indicating a mechanism that may be selective for nonpathogenic microbes. The involvement of peroxidases and oxylipins, both known to be released by roots in response to stress, was demonstrated by using $R E$ fractions containing these molecules or their commercial purified analogs, testing the effect of an inhibitor, and characterizing the complex pattern of these metabolites released by tomato roots both locally and systemically.
\end{abstract}

The soil zone surrounding the root system is influenced by the release of organic compounds from the plant, which affect the presence and activity of numerous and diverse microorganisms. The resulting plant-microbiome interaction plays a key role in essential functions, such as nutrient uptake and disease resistance or susceptibility. Some rhizosphereassociated microbes are able to protect the host from soil

${ }^{\dagger}$ Corresponding author: Matteo Lorito; E-mail: lorito@unina.it

Funding: This work has been supported by i) Ministry of Education, University and Research grants LINFA PON03PE_00026_1; ii) Marea PON3PE_00106_1; and iii) SICURA grant number DM29156; iv) PON project GenoPom Pro OR1 "Analysis of networks that regulate the response of the plant to the environment"; v) POR Campania CARINA FSE 2007 2013, Asse V; vi) Ministries of Foreign Affairs and International Cooperation "Development of new biopesticides for integrated control of various pests in agriculture" Project Italy-Canada (Quebec) PGR00167; vii) European Commission Seventh Framework Programme Integrated Pest Management project PURE: Pesticide Use-and-risk Reduction in European farming systems; viii) Regione Campania BIP; ix) the European Commission Marie Curie ITN FUNGIBRAIN (FP7-PEOPLE-ITN-607963); and ix) Spanish Ministerio de Economía y Competitividad (MINECO) grant BIO2013-47870-R.

(C) 2018 The American Phytopathological Society pathogen attack, but their efficacy is strongly determined by the presence of other soil microorganisms, due to the complex relationships that are established (Berendsen et al. 2012). There is an increased recognition of the importance of the root exo- and endo-microbiome, as it can provide benefits in terms of protection from stresses, increased nutrient availability, growth promotion, enhanced yield, and product quality (Berg et al. 2014; Lebeis 2014; Trivedi et al. 2016). Specific biotic or abiotic stresses, or both (such as pathogen attack and water or nutrient deficiency), can regulate the composition of the plant microbiome, in particular, the microbial population is able to stimulate and help the plant to react, allowing the constraint, in some cases, to be overcome (Berendsen et al. 2012). For example, infection by the fungal pathogen Verticillium dahliae increased the population of beneficial bacteria Pseudomonas sp. strain LBUM300 in the microbiome of strawberry plants. Also, attack by this pathogen modified the rhizosphere composition of cotton plants in favor of members of the phyla Deinococcus-Thermus and Firmicutes (DeCoste et al. 2010; Zhang et al. 2011). Fons et al. (2003) demonstrated that the microbial composition of the Trifolium subterraneum rhizosphere could be altered by adding saponins secreted by Gypsophila paniculata. Recently, Neal and Ton (2013) reported that the secretion of the phytotoxic metabolite 2,4dihydroxy-7-methoxy-2H-1,4-benzoxazin-3(4H)-one (DIMBOA) made the maize rhizosphere more attractive to the bacteria Pseudomonas putida involved in plant protection.

Plant roots exude a variety of low molecular-weight compounds that can increase the microbial activity in the rhizosphere (Bais et al. 2006; Oger et al. 2004). The composition of root exudates (RE) depends on different factors, including the plant species or variety, the physiological status or phenological development stage, or the soil environment (Doornbos et al. 2012; Haichar et al. 2008; Neal and Ton 2013). RE play an important role in the interactions between plants and the soil microbial community. Specific molecules can act as chemical signals by repressing or stimulating growth and development of various microorganisms, therefore regulating structure and activity of the rhizosphere microbiome (Bais et al. 2006). For instance, Kamilova et al. (2006a) reported that secretion of citrate by tomato roots enriched the presence of rhizobacteria that are excellent root-tip colonizers. Also, isoflavones released by soybean roots attracted the nodulating symbiont Bradyrhizobium japonicum as well as the pathogen Phytophthora sojae (Morris et al. 1998).

When under attack by soilborne pathogens, plants can modify both the quantity and the composition of their RE 
(Bezemer and van Dam 2005), e.g., by producing antimicrobial compounds that differentially affect microbial species in the rhizosphere (Berendsen et al. 2012). Infection of barley roots with Pythium ultimum induced accumulation of phenolic and organic acids in the RE, with concentrations of vanillic, p-coumaric, and fumaric acids increasing up to fourfold (Jousset et al. 2011). Similarly, infection of sweet basil with Pythium spp. led to the release of antimicrobial compounds such as caffeic acid ester and rosmarinic acid (Bais et al. 2002), whereas Fusarium attack of barley roots stimulated the production of antifungal phenolics (Lanoue et al. 2010).

Recent studies have demonstrated that plants exposed to stress conditions can recruit beneficial microorganisms at the expense of detrimental ones. For instance, attack by white fly (Bemisia tabaci) enhanced the expression of pathogenesis-related protein genes and elicited resistance in sweet pepper against the bacterial vascular pathogen Ralstonia solanacearum, possibly by increasing the rhizosphere population of beneficial gram-positive bacteria and fungi (Yang et al. 2011). Lee et al. (2012) demonstrated that foliar feeding by aphids (Myzus persicae) increased the population of the beneficial Bacillus subtilis GB03 while reducing the presence of the pathogen $R$. solanacearum. Battaglia et al. (2013) reported that root colonization by Trichoderma spp. can modify the pattern of volatile organic compounds (VOCs) released by tomato in a manner that increased the attraction of both a parasitoid and a predator to the leaves attacked by the aphid Macrosiphum euphorbiae.

Trichoderma spp. have been extensively studied and are among the most abundantly used biological control agents of diverse plant diseases in various agricultural crops worldwide (Lorito et al. 2010; Woo et al. 2014). Many strains are able to either form endophytic associations with the plant, establish interactions with other microorganisms in the rhizosphere, or both. This has been linked to observed beneficial effects on the plant, including increased resistance or tolerance to biotic or abiotic stresses as well as enhanced growth and development (Harman et al. 2004; Hermosa et al. 2012; Vinale et al. 2008b). Some strains improve nutrient use efficiency by solubilizing phosphate and micro- and macro-nutrients, thus favoring their uptake by the plant (Altomare et al. 1999; de Santiago et al. 2011). Further, it has been reported that some secondary metabolites produced by Trichoderma spp. have an auxin-like activity on pea (Pisum sativum), tomato (Solanum lycopersicum), and canola (Brassica napus) seedlings (Vinale et al. 2008a). Trichoderma interaction with roots has been extensively studied in many plants, including tomato, to determine the fungal molecules involved and their mechanism of action (Lorito et al. 2010; Vinale et al. 2008b; Woo et al. 2006) as well as the effects on the proteome, metabolome, expressome, and, in general, on the physiology of the plant (Lorito et al. 2010; Marra et al. 2006). However, nothing is known, at least to our knowledge, about the compounds of root origin able to specifically affect Trichoderma colonization and beneficial activity. On the contrary, recent findings have identified root-secreted factors (peroxidases) that attract pathogenic F. oxysporum toward the host plant, in particular tomato (Turrà et al. 2015). Therefore, it would be important to determine both similarities and differences in the response of these two ubiquitous and oppositeacting soil fungi to plant chemical signals in the presence and the absence of a stress factor.

The aim of this work was to study plant responses to treatments with biotic and abiotic stresses in terms of production of $\mathrm{RE}$ that may recruit or attract beneficial and pathogenic soil fungi. A chemotropism assay on agar plates (Turrà et al. 2015) was used to evaluate the chemoattractant activity of RE toward Trichoderma harzianum and Fusarium oxysporum. We also tested the chemotropic effect of plant peroxidases, which were recently reported to direct growth of $F$. oxysporum toward the roots (Turrà et al. 2015), and of oxylipins, which are synthetized primarily during the interaction with pathogens or insects and, also, as a result of wound stress (Siebers et al. 2016). However, the mechanisms of oxylipins formation are complex (Howe and Schilmiller 2002) and are not fully clarified.

Results presented here indicate that both types of root-secreted compounds, peroxidases and oxylipins, act as chemical signals able to either attract, stimulate, or both the beneficial fungus T. harzianum. This evidence is in line with the well-known cases of beneficial insects attracted by VOCs in response to pest attack (Battaglia et al. 2013; Halitschke et al. 2008; Kessler and Baldwin 2001). New knowledge presented in this work contributes to the understanding of how roots influence the rhizosphere microbiome, thus promoting plant-microbe interactions that produce positive effects on crops.

\section{RESULTS}

Pathogen-challenged plants promote Trichoderma growth.

The effect of infection by a foliar pathogen (Botrytis cinerea) on the growth rate of $T$. harzianum, inoculated in close proximity to tomato and cucumber roots, was evaluated in vitro (Fig. 1A). In both plant species, the colonies of the beneficial fungus developed faster in the presence of a diseased plant in comparison with a water-inoculated control (Table 1; Fig. 2), indicating the presence of a systemic signal that causes release at the root level of diffusible compounds able to stimulate Trichoderma growth. For tomato, the registered increase in the fungus colony size reached $200 \% 1$ day postinoculation (dpi) and was partially maintained over time, with values of about +60 and $+48 \%$, respectively, 2 and 3 dpi (Fig. 2). Similar results were obtained with cucumber, in which the observed percentage of increased growth vs. control was 79,69 , and $61 \%$, respectively at 1,2 , and 3 dpi (Table 1).

\section{Root exudates from stressed plants differentially attract soil fungi.}

Root exudates (RE) were obtained from tomato plants grown in a split-root system and subjected to biotic (pathogenic or nonpathogenic fungi) or abiotic (i.e., high salt or wounding) stresses (Fig. 1B). RE obtained from the not directly exposed or the directly exposed side of the split roots (solutions 1 and 2, respectively) were concentrated and were used in a microscopebased assay (Turrà et al. 2015), to evaluate their chemoattractant activity toward T. harzianum or F. oxysporum (Fig. 1C and D).

In general, the percentage of Trichoderma spores germinating or germ tubes elongating toward RE obtained from roots exposed indirectly or directly to stress agents (solutions 1 and 2) was significantly higher (Student's $t$ test, $P<0.0001$ ) than those growing toward RE produced by the water controls (Fig. 3A). Interestingly, a similar response was observed in the case of plants treated with $T$. harzianum $\mathrm{T} 22$, although only with RE from the roots that had not been directly in contact with the beneficial fungus (T22-1) (Fig. 3A).

The RE from the various treatments induced different levels of chemotropic responses in the germinating spores. Wounding and the salt- 2 treatment caused the most significant changes in reorientation of $T$. harzianum germ tubes, with an up to twofold higher chemotropic index value compared with the untreated control (Fig. 3A).

Interestingly, microconidia of $F$. oxysporum exposed to the same RE exhibited distinct chemotropic responses (Fig. 3B). Only two treatments (T22-1, F.oxy fmkl $\Delta-1$ ), both obtained from the side of the roots not directly exposed to treatment, produced a higher chemotropic index, statistically different from the control 
(Student's $t$-test, $P<0.0001)$. A particularly high chemotropic index (20.5) was noted when RE obtained from the untreated side of the roots of $T$. harzianum treated plants (T22-1) were used (Fig. 3B), while similar samples obtained from nonpathogenic F. oxysporum-treated plants reached a value of 14.1 (F.oxy fmk $1 \Delta$ 1) (Fig. 3B). The effect of boiling the RE before application was tested for the two samples that scored the highest chemotropic index on T. harzianum (wounding, salt-2 treatments) and Fusarium (T22-1) germlings. The heat treatment decreased significantly the chemotropic attraction in all cases (Fig. 4A and B).

\section{Stress-induced peroxidase activity and oxylipins trigger chemotropism in Trichoderma harzianum.}

RE were positively tested for secreted peroxidase activity, which differed considerably between plants subjected to the various treatments (solutions 1 and 2). The enzyme activity was statistically different from the control only for the samples F.oxy $f m k 1 \Delta-1$ and T22-2 that exhibited a value of $7.58 \times 10^{-6}$ units per milliliter and $6.82 \times 10^{-6}$ units per milliliter, respectively (Fig. 5). However, the peroxidase activity was always completely lost when samples were boiled for $20 \mathrm{~min}$ at $100^{\circ} \mathrm{C}$ (Fig. 5). RE were divided in two fractions, using a 3-kDa cut-off membrane. All the $>3-\mathrm{kDa}$ fractions obtained from the RE of both treated and untreated tomato plants elicited a chemotropic response in T. harzianum germ tubes. However, five of the nine tested

A

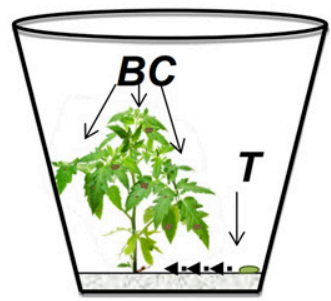

B

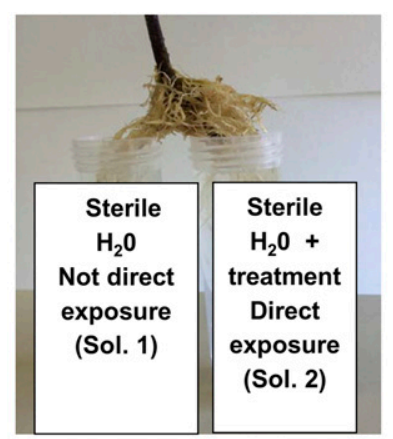

C

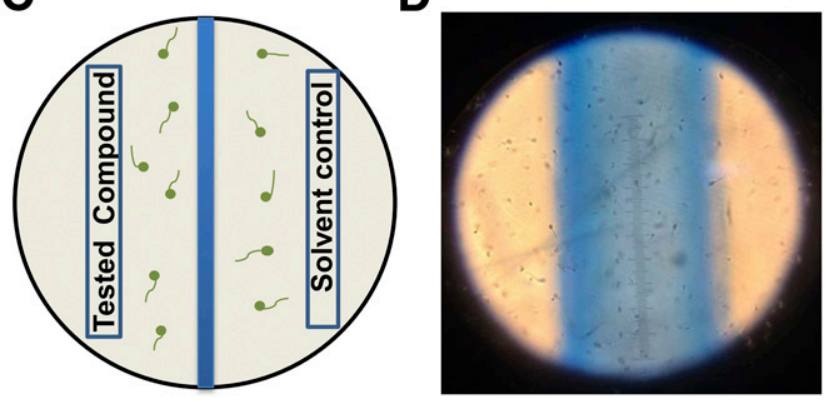

Fig. 1. Schematic representation of the experiment setup. A, In-vitro fungal colony growth assay. Leaves of a tomato plant grown in Murashige Skoog $(\mathrm{MS})+1 \%$ agar were drop-inoculated with Botrytis cinerea $(B C)(10 \mu \mathrm{l}$ of a $1 \times 10^{6}$ spore $\mathrm{ml}^{-1}$ suspension); after $12 \mathrm{~h}$, a spore suspension of Trichoderma harzianum T22 (T) $\left(20 \mu \mathrm{l}\right.$ of a $1 \times 10^{7}$ spores per milliliter $)$ was applied to the substrate surface. Radial growth of the fungal colony toward the plant was measured daily (dotted arrows). B, Tomato split-root system used to produce root exudates (RE). Each root part was immersed in a 50-ml sterile water solution; one side remained in sterile water $\left(\mathrm{H}_{2} \mathrm{O}\right)$ and the collected RE was named solution 1 (Sol. 1), whereas roots on the other side were directly subjected to different biotic or abiotic stress treatments and the collected RE was named solution 2 (Sol. 2). C and D, Chemotropism assay plate (schematic representation and actual microphotograph). Tested compound and solvent control were applied to the parallel grooves obtained in the water agar, and the direction of the germ-tube growth was evaluated for a total of 500 germlings. fractions produced a significantly higher chemotropic index compared with the control (Student's $t$-test, $P<0.0001$ ) (Fig. 6). In particular, samples collected from the side of the roots not directly exposed to the stress of the nonpathogenic F. oxysporum and salt-treated plants (F.oxy $f m k 1 \Delta-1$ and salt-1) showed a chemotropic index of 12.2 and 11.7, respectively, while the control reached a value of 9.8 (Fig. 6). Interestingly, a similar response was also observed for exudates obtained from the roots that had been directly in contact with $T$. harzianum T22 (T22-2) (Fig. 6).

Commercially available horseradish peroxidase (HRP) triggered a positive chemotropic response in $T$. harzianum germ tubes, resulting in a chemotropic index of 8.1 and 13.8 when used at concentrations of 4 and $256 \mu \mathrm{M}$, respectively (Fig. 7). The chemoattractant effect of HRP was completely lost after boiling (Fig. 7). Furthermore, RE samples from control and wounding were selected as representative treatments to test the effect of the concurrent application of salicylhydroxamic acid (SHAM), an inhibitor of peroxidase activity. In both cases, the inhibitor decreased the effect and, thus, the chemotropism index value by about $50 \%$ (Fig. 8).

All RE were analyzed for oxylipin content. The total amount of oxylipins detected in RE varied among the treatments, whereby seven of the nine RE, as found in both sides of the split roots (solutions 1 and 2), obtained from five tested conditions, showed an increased oxylipin content compared with the water control (Fig. 9). Only the treatment with the pathogenic Fusarium strain (F.oxy-1 and F.oxy-2) did not affect total oxylipin concentration in the RE.

Further, liquid chromatography and mass spectrometry (LC/MS) analysis indicated that the various treatments specifically modified the amount and the composition of the oxylipins secreted on both sides of the split-root system (solutions 1 and 2), as compared with controls (Table 2). Interestingly, the increase in oxylipin production was particularly high for the epoxide of linoleic acid (12,13-epOME) in the samples obtained from treatment with salt and T22 (solution 1, no direct exposure). In fact, the amount of 12,13-epOME was seven and six times greater than in controls, respectively, for salt-1 and T22-1 (Table 2).

The RE tomato oxylipins were then extracted from the $<3$ $\mathrm{kDa} \mathrm{RE}$ fraction and were tested for activity. They triggered a chemotropic response in the beneficial fungus $T$. harzianum statistically higher as compared with the control, except for the treatment from the direct contact with the pathogenic Fusarium strain (F.oxy-2). Wounding and salt-2 treatments determined the highest chemotropic index values (15.6 and 18.1, respectively), while the control showed a chemotropic index of 7.9 (Fig. 10).

T. harzianum reacted positively in terms of chemotropic attraction to treatments with four different commercial oxylipins used in a range of concentrations (Fig. 11A). The strongest response was obtained at $10 \mu \mathrm{M}$, with the $13 \mathrm{sHODE}$ scoring the highest chemotropic index (14.5) (Fig. 11A). Interestingly, the chemoattraction by all four commercial oxylipins at $10 \mu \mathrm{M}$ was lost when the concentration was too low $(2.5 \mu \mathrm{M})$ or too high $(80 \mu \mathrm{M})$ as well as after boiling (Fig. 11B).

\section{DISCUSSION}

Plants modulate the composition of the associated microbiome by applying a selection pressure that produces substantial changes in the microbial population, with a resulting profile that can be different even among varieties of the same plant species (Badri et al. 2009; Bressan et al. 2009; İnceoğlu et al. 2010, 2011; Micallef et al. 2009; Weinert et al. 2009). 
Roots can change the function and the structure of the rhizosphere microbiome through the secretion of molecules that stimulate or repress growth and activity of microorganisms (Doornbos et al. 2012). The role of RE in shaping the microbial community has been described (Bais et al. 2006; Berendsen et al. 2012; Kamilova et al. 2006b; Raaijmakers et al. 2015; Thijs et al. 2016) and related to plant health or development status (Paterson et al. 2006). Indeed, communication between host and the root microbiome is affected by stress or pathogen presence (Berendsen et al. 2012), which may cause an increased attraction or promotion of beneficial microorganisms that may help to overcome the constraint. Mark et al. (2005) observed a correlation between beneficial Pseudomonas aeruginosa gene expression and exposure to REs produced by two varieties of sugar beet. Mavrodi et al. (2012) reported that wheat infected by Gaeumannomyces graminis recruits populations of Pseudomonas spp. that produce the antibiotic 2,4diacetylphloroglucinol. The same plant species may be able to make populations of Pseudomonas spp. dominant in soils when the pathogen Rhizoctonia solani is detected. Also, in the case of the formation of arbuscular mycorrhiza (AM), roots release metabolites such as strigolactones (Akiyama et al. 2005) that may attract the appropriate microbes. Buee et al. (2000) reported that REs of Daucus carota L. triggered branching of germlings of Gigaspora gigantea, G. rosea, and G. margarita, whereas the volatile compounds produced by corn and bean roots induced directional bending of $G$. gigantea hyphae (Besserer et al. 2006; Koske 1982).

In this work, we demonstrate that, in tomato plants, different biotic or abiotic stresses elicit the secretion of molecules by the root that increase the chemoattractive effect on the beneficial soil microbe $T$. harzianum. Tomato or cucumber plants inoculated with a foliar pathogen were generally more growthstimulating to the fungus than the healthy controls. Assays were also performed on cucumber because the tested Trichoderma strain is known to be effective in terms of both biocontrol effect and rhizosphere competence on a variety of species. This indicates that an effective biocontrol Trichoderma strain, similarly to other beneficial soil microbes, may have developed the ability to sense and respond to stress-induced metabolic changes reflected in the RE composition. This function could be related to the well-known direct effects of Trichoderma root colonization, which may be beneficial for both the fungus and the plant (Hermosa et al. 2012; Shoresh et al. 2010). In addition, we found that the attraction process is active, directional, and expressed systemically in the plant. To demonstrate this concept, we used a split-root system, with one part of the roots maintained in water only and the other part subjected to the treatment. A similar method was used by Jousset et al. (2011) to show that roots of barley plants challenged with a pathogen stimulate antifungal activity in the rhizosphere microflora. In our experiments, germ tubes of Trichoderma spp. were clearly and directionally more attracted by compounds released by roots of plants subjected to abiotic stress, in particular, stem wounding and salt, than by those from untreated plants (Fig. 3A). The chemoattractant effect appears to be transmitted to the entire root system, since solutions obtained from both sides of the split root were active. Similarly, the treatment with $T$. harzianum T22 affected RE both locally and systemically and produced a positive chemoattractant effect on the same fungus. This result seems to be in agreement with that of Lace et al. (2015), who demonstrated microscopically that the contact of $T$. harzianum with the root of Medicago truncatula may activate a strong response, even resulting in cell

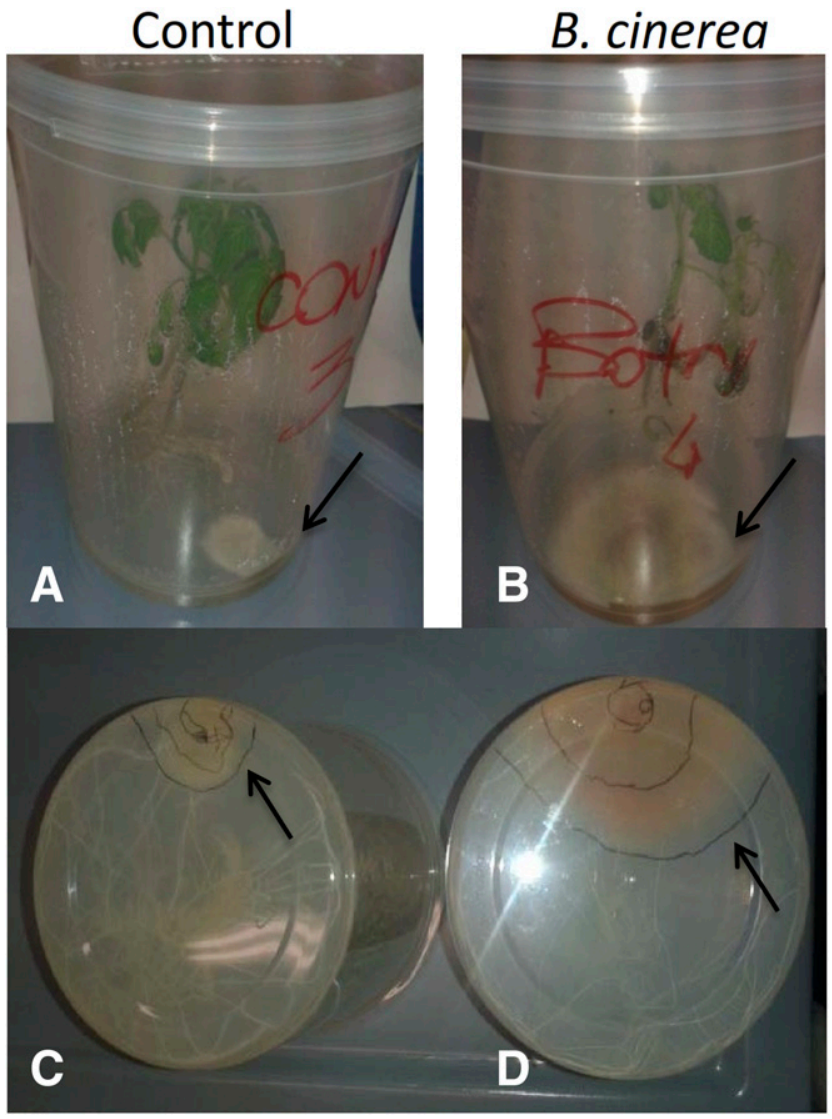

Fig. 2. Effect of tomato plants inoculated with the foliar pathogen Botrytis cinerea on the radial growth of Trichoderma harzianum T22. A and B, Front and $\mathbf{C}$ and $\mathbf{D}$, bottom views of plants grown in vitro and inoculated with a 10- $\mu$ l drop of a Botrytis cinerea spore suspension $\left(1 \times 10^{6}\right.$ spores $\left.\mathrm{ml}^{-1}\right)$ (B and D) or water (control) (A and C). After infection, a 20- $\mu$ d drop of a T22 spore suspension $\left(1 \times 10^{7}\right.$ spores $\left.\mathrm{ml}^{-1}\right)$ was applied distally. Arrows indicate the periphery of the T22 colony measured 3 days postinoculation.

Table 1. In-vitro tests to determine the effects of tomato and cucumber plants inoculated with the foliar pathogen (Botrytis cinerea) or water (control) on the mycelial radial growth of Trichoderma harzianum ${ }^{\text {a }}$

\begin{tabular}{|c|c|c|c|c|c|c|}
\hline \multirow[b]{2}{*}{ Day } & \multicolumn{3}{|c|}{ Tomato } & \multicolumn{3}{|c|}{ Cucumber } \\
\hline & B. cinerea & Control & Growth increase $(\%)$ & B. cinerea & Control & Growth increase $(\%)$ \\
\hline 1 & $1.02 \pm 0.40 * *$ & $0.34 \pm 0.05$ & 200 & $1.00 \pm 0.36^{*}$ & $0.56 \pm 0.05$ & 78.57 \\
\hline 2 & $2.02 \pm 0.38 * * *$ & $1.26 \pm 0.23$ & 60.32 & $1.96 \pm 0.27 * * *$ & $1.16 \pm 0.23$ & 68.97 \\
\hline 3 & $3.46 \pm 0.45^{* * *}$ & $2.34 \pm 0.50$ & 47.86 & $3.64 \pm 0.30 * * *$ & $2.26 \pm 0.38$ & 61.06 \\
\hline 4 & $4.66 \pm 0.59 * * *$ & $3.56 \pm 0.38$ & 30.9 & $4.78 \pm 0.24 * * *$ & $3.34 \pm 0.21$ & 43.11 \\
\hline 5 & $5.5 \pm 0.00^{* *}$ & $4.82 \pm 0.36$ & 14.11 & $5.50 \pm 0.00 * * *$ & $4.54 \pm 0.37$ & 21.15 \\
\hline
\end{tabular}

a Colony size is shown in centimeters. Data are expressed as the mean value of three experiments \pm standard deviation, analyzed by two-way analysis of variance (ANOVA). Means are significantly different compared with control, as indicated by ANOVA least significant difference $(* P<0.05, * * P<0.01$, $* * * P<0.001)$. 
apoptosis, although different than that induced by a pathogen. Therefore, it has been proposed that the strong reaction of the plant to contact with some Trichoderma strains is involved in the priming of the defense response to a pathogen attack (Hermosa et al. 2013).

F. oxysporum germ tubes also showed a positive chemotropism toward RE from roots treated with $T$. harzianum or with a nonpathogenic Fusarium mutant but not from the side directly exposed to these stimuli or from abiotically stressed plants (Fig. 3B). In the last cases, a sort of "repellent" reaction was observed, since a significantly lower number of germ tubes turned to the direction of the treatment sample compared with the water control. A similar response was registered by triggering Fusarium germlings with RE obtained by challenging the plant with pathogenic Fusarium spp. (both sides of the root), wounding, or salt. Our data clearly indicates that Trichoderma and Fusarium germinating spores respond very differently to compounds released by the roots of stressed plants. The molecular mechanisms behind this phenomenon are unknown. A plausible hypothesis is that the tomato plant can selectively increase or reduce chemoattraction or activity of beneficial root-colonizing fungi vs. pathogens under certain stress conditions. Actually, the most "attractive" treatments for $T$. harzianum were wounding and salt, whereas these conditions produced RE less attractive for Fusarium spp. than those from untreated plants. Therefore, another possibility is that some biocontrol agents may have developed the ability to sense a wider range of stress-related signals than plant pathogens.

RE contain a range of chemical compounds that can be classified into two general groups, low molecular-weight (i.e., some phenols, small polysaccharides, amino acids, organic acids) and high molecular-weight compounds (i.e., large carbohydrates, fatty acids, flavonoids, enzymes, tannins, steroids, terpenoids, alkaloids, polyacetylenes, and vitamins) (Bais et al. 2006; Bertin et al. 2003). Some of these have been reported to act as chemoattractants of soil microbes, independently of a nutritional effect, during both pathogenic and beneficial interactions. The first report could be that of Massee (1905), who identified malic acid and pectate as compounds involved in the attraction of either parasites or saprophytes. More recently, Turrà et al. (2015) demonstrated that the growth of the plant pathogen $F$. oxysporum toward the roots of the host tomato (S. lycopersicum) is stimulated by secreted class III peroxidases. Moreover, the release of the isoflavones genistein and daidzein by soybean roots caused a chemotropic effect on Phytophthora sojae (Morris et al. 1998), while isovaleraldehyde was found to specifically attract the zoospores of Phytophthora palmivora (Cameron and Carlile 1981).

In the case of beneficial microorganisms, Arabidopsis plants whose leaves were infected by Pseudomonas syringae selectively recruited the soil bacterium Bacillus subtilis FB17 over

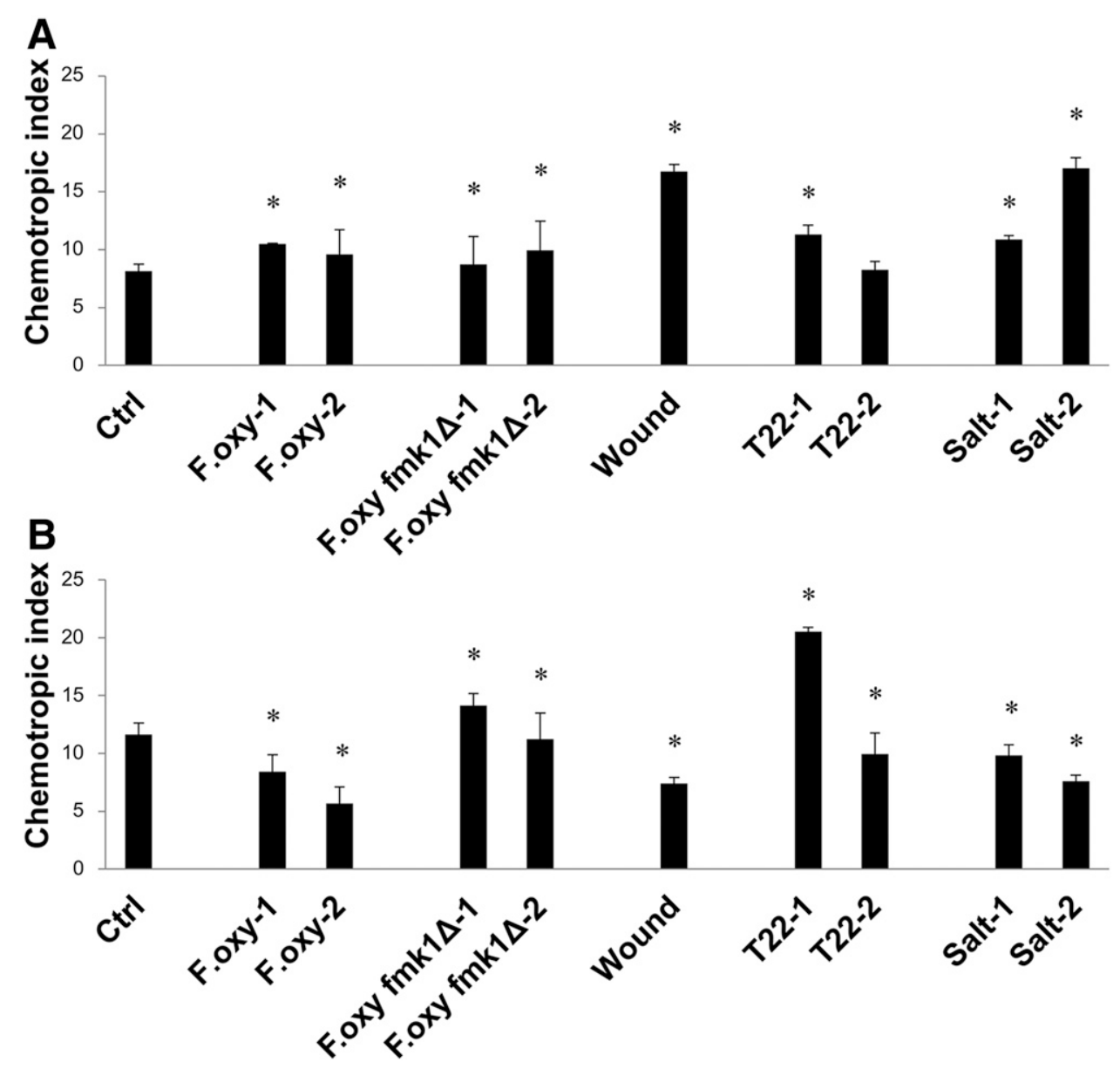

Fig. 3. Chemotropic activity of tomato root exudates, obtained as indicated below, on A, Trichoderma harzianum germ tubes and B, Fusarium oxysporum germ tubes. The chemotropic index was scored after $13 \mathrm{~h}$ of incubation at room temperature. Treatments in the split-root assay include: Ctrl $=$ split roots in which both sides were immersed in water; F.oxy-1 and F.oxy-2 = split root in which one side was immersed in water (F.oxy-1) and the other side was exposed to spores of the pathogenic F. oxysporum (F.oxy-2); F.oxy fmk1 $\Delta-1$ and F.oxy fmk1 $\Delta-2=$ split root in which one side was immersed in water (F. oxy fmk1 $\Delta-1)$ while the other side was exposed to spores of a nonpathogenic $F$. oxysporum strain (F.oxy fmk $1 \Delta-2$ ); Wound = artificial injury was inflicted to the stem, then both sides of the root were immersed in water; T22-1 and T22-2 = split root in which one side was immersed in water (T22-1) and the other side was exposed to T. harzianum T22 spores (T22-2); salt-1 and salt-2 = split root in which one side was immersed in water (Salt-1) and the other side was exposed to $100 \mathrm{mM}$ NaCl (Salt-2). Data are presented as the mean of three experiments. Error bars indicate standard deviation. An asterisk $(*)$ indicates values that are significantly different from the water control $(P<0.0001)$. 
other rhizobacteria by secreting malic acid (Rudrappa et al. 2008). Similarly, the AM fungus Gigaspora margarita responded to the presence of strigolactones released from the roots of Lotus japonicus (Akiyama et al. 2005).
In our work, we tested, in vitro, the occurrence of chemoattractant mechanisms for a biocontrol strain of Trichoderma spp. that has been commercially used worldwide for more than 20 years and is considered to be one of the best-studied
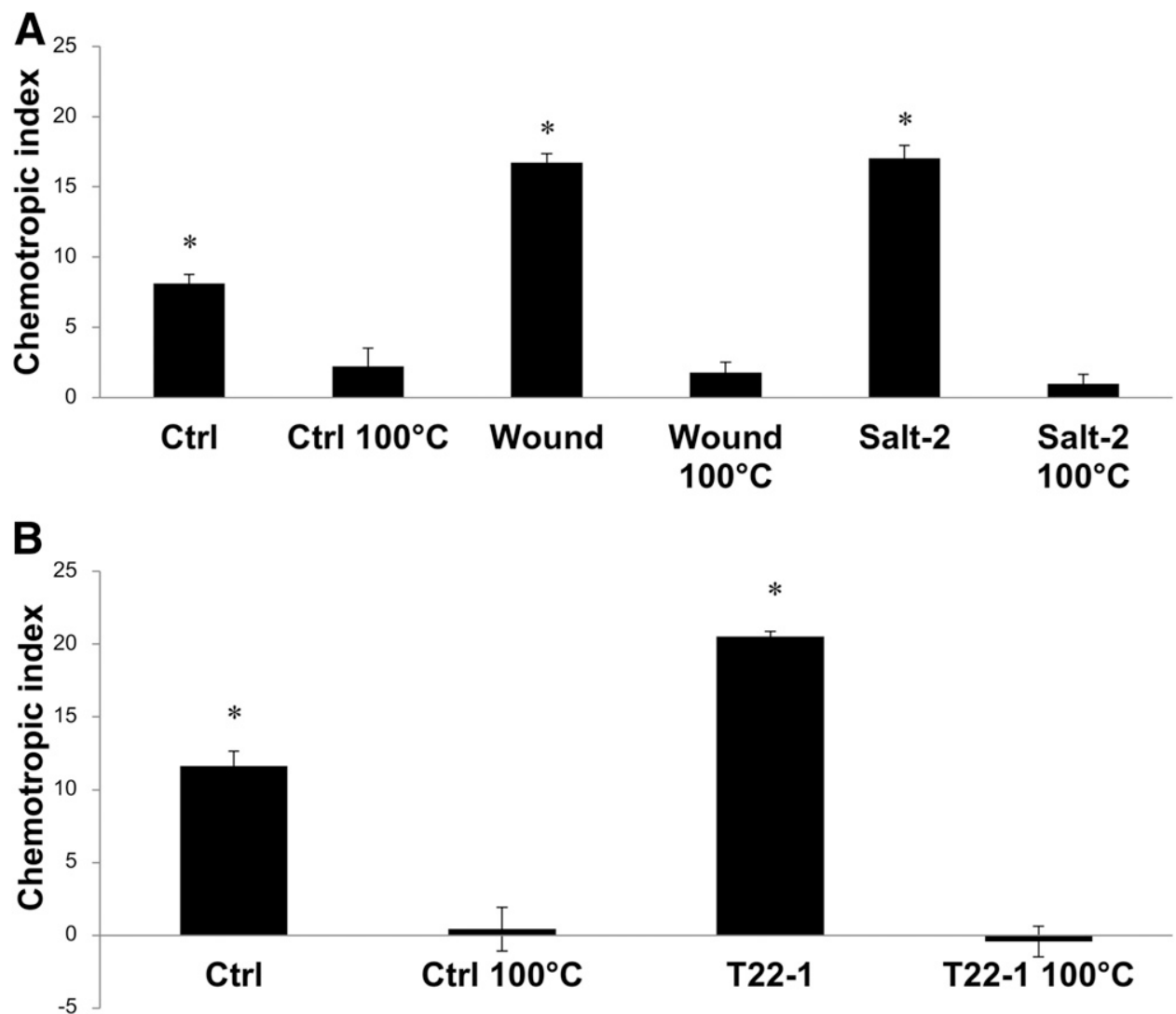

Fig. 4. Effect of boiling on the chemotropic activity of tomato root exudates (RE) on A, Trichoderma harzianum and B, Fusarium oxysporum germ tubes. Only the two RE samples that scored the highest chemotropic index value were tested. Data are presented as the mean of three experiments. Error bars indicate standard deviation. An asterisk (*) indicates values that are significantly different between the untreated RE and the boiled RE $(P<0.0001)$.

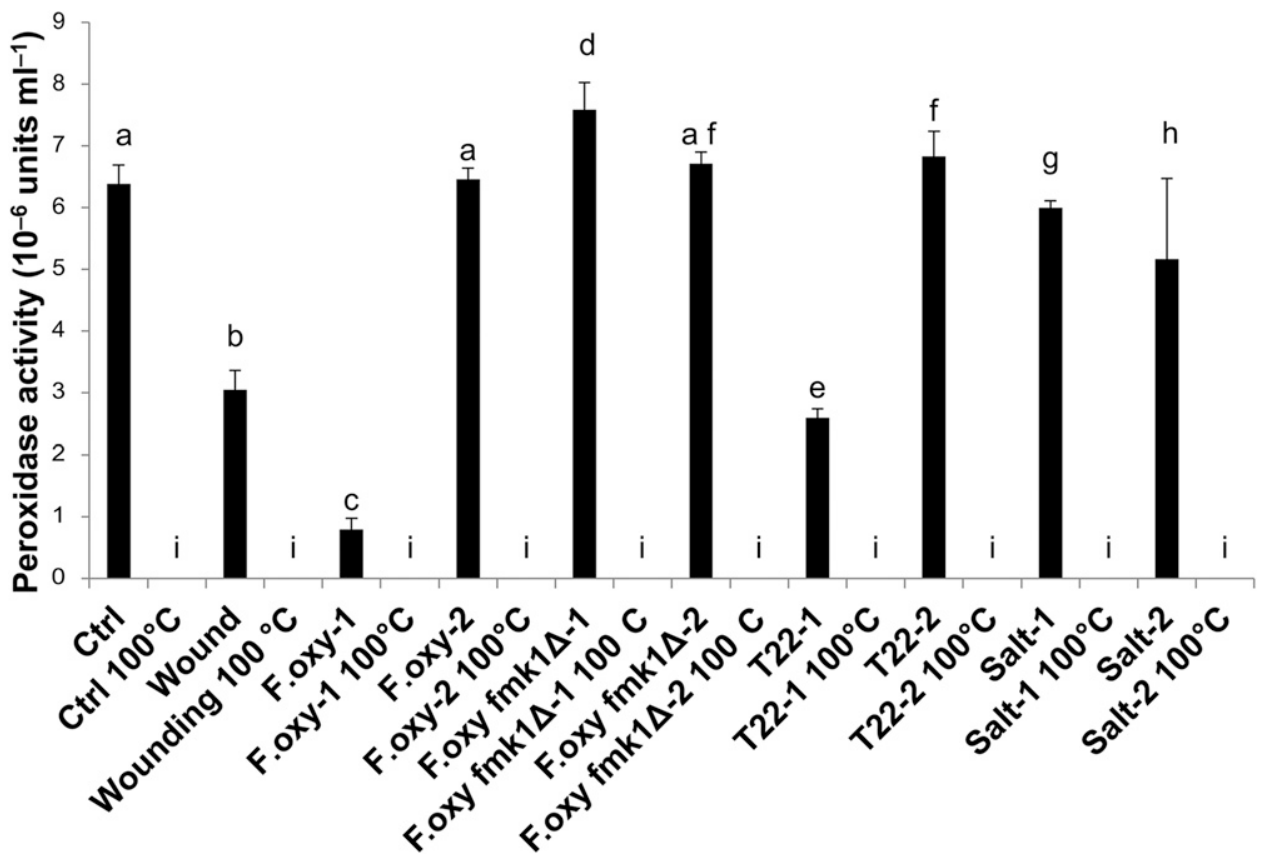

Fig. 5. Peroxidase activity in tomato root exudates (RE) obtained by the split-root assay. The term " $100^{\circ} \mathrm{C}$ " indicates that the $\mathrm{RE}$ was boiled at $100^{\circ} \mathrm{C}$ for $22 \mathrm{~min}$. (All RE values after the $100^{\circ} \mathrm{C}$ treatment were zero and were not significantly different as indicated by "i"). Data are presented as the mean of three experiments \pm standard deviation. Statistical analysis was performed by two-way analysis of variance; values with the same letter are not significantly different, as determined by least significant difference test at the $5 \%$ level of significance. 
microbes in biological control (Woo et al. 2014). We identified specific molecules systemically released by tomato roots during the initial phase of the stress response, which act as chemoattractants for this beneficial fungus. Once the effect was detected, we directly tested compounds already known to be released by plant roots in response to stress and found that peroxidases and oxylipins function as chemoattractants for Trichoderma harzianum.

Peroxidases are present in all land plants and they are involved in different physiological processes, such as defense mechanisms against pathogens (Passardi et al. 2004; Turrà et al. 2015). We evaluated the peroxidase activity in the REs of tomato plants and we observed changes according to the different stress condition applied (Fig. 5). Interestingly, the indirect application of a nonpathogenic Fusarium mutant (F.oxy fmkl $\Delta$-1) and the direct application of Trichoderma spores (T22-2) lead to a significant increase of peroxidase activity compared with control (Fig. 5) and to a likewise significant increase of the chemotropic index of the corresponding $>3-\mathrm{kDa} \mathrm{RE}$ fractions (Fig. 6). Furthermore, the REs obtained by wound and salt-2 treatments, which scored the highest chemotropic index on Trichoderma harzianum (Fig. 3A), showed a peroxidase activity and chemotropic index significantly lower than control (Figs. 5 and 6). This evidence suggests that the high values of chemotropic index recorded for these treatments may be related not only to peroxidases but is the result of a synergistic action of multiple compounds.

Oxylipins are secondary metabolites produced by the oxidative transformation of polyunsaturated fatty acids, are involved in the activation of local and systemic responses to various stresses (Howe and Schilmiller 2002; Santino et al. 2010), and may have antimicrobial properties (Feussner and Wasternack 2002; Prost et al. 2005). Different stress factors could determine the destruction of cellular tissue and the subsequent hydrolysis of glycerolipids by endogenous acylhydrolases, leading to the release of polyunsaturated fatty acids containing a conjugated diene, such as linoleic acid, and their subsequent oxidation by lipoxygenases (LOX) (Matsui
2006). The presence of a variety of LOX isoforms allows the synthesis of different oxylipins in response to various stress signals (Blée 2002; Howe and Schilmiller 2002). Conditions such as wounding or pathogen attack induce LOX activity and lead to a strong increase in the content of polyunsaturated fatty acid derivatives (Blée 2002; Weichert et al. 1999). Here, we report that different stresses lead to significant changes, both quantitatively and qualitatively, in the composition and concentration of oxylipins in the RE (Fig. 9; Table 2).

We analyzed and characterized the eight different oxylipins found in the RE (Table 2) and demonstrated that, in most cases, the stress treatments increased the concentration of these metabolites (Fig. 9; Table 2). Interestingly, the changes were detected both in solution 1 and solution 2 . In a few cases, the effect was even more pronounced in the root side that was not

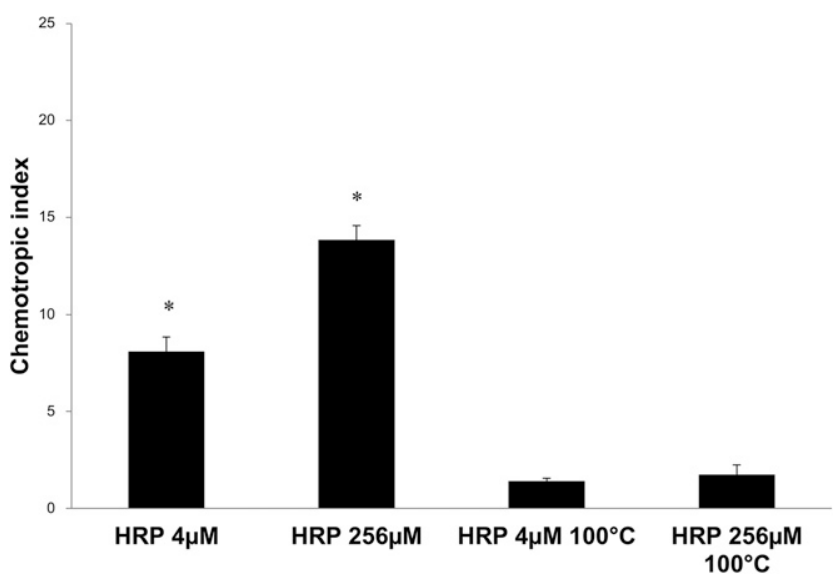

Fig. 7. Chemotropic activity of horseradish peroxidase (HRP) on the growth of Trichoderma harzianum germ tubes, applied at different concentrations (4 and $256 \mu \mathrm{M})$, also after boiling $\left(100^{\circ} \mathrm{C}\right.$, for $\left.22 \mathrm{~min}\right)$. Data are presented as the mean of three experiments. Error bars indicate standard deviation. An asterisk $(*)$ indicates values that are significantly different between the untreated HRP and the boiled HRP, $P<0.0001$.

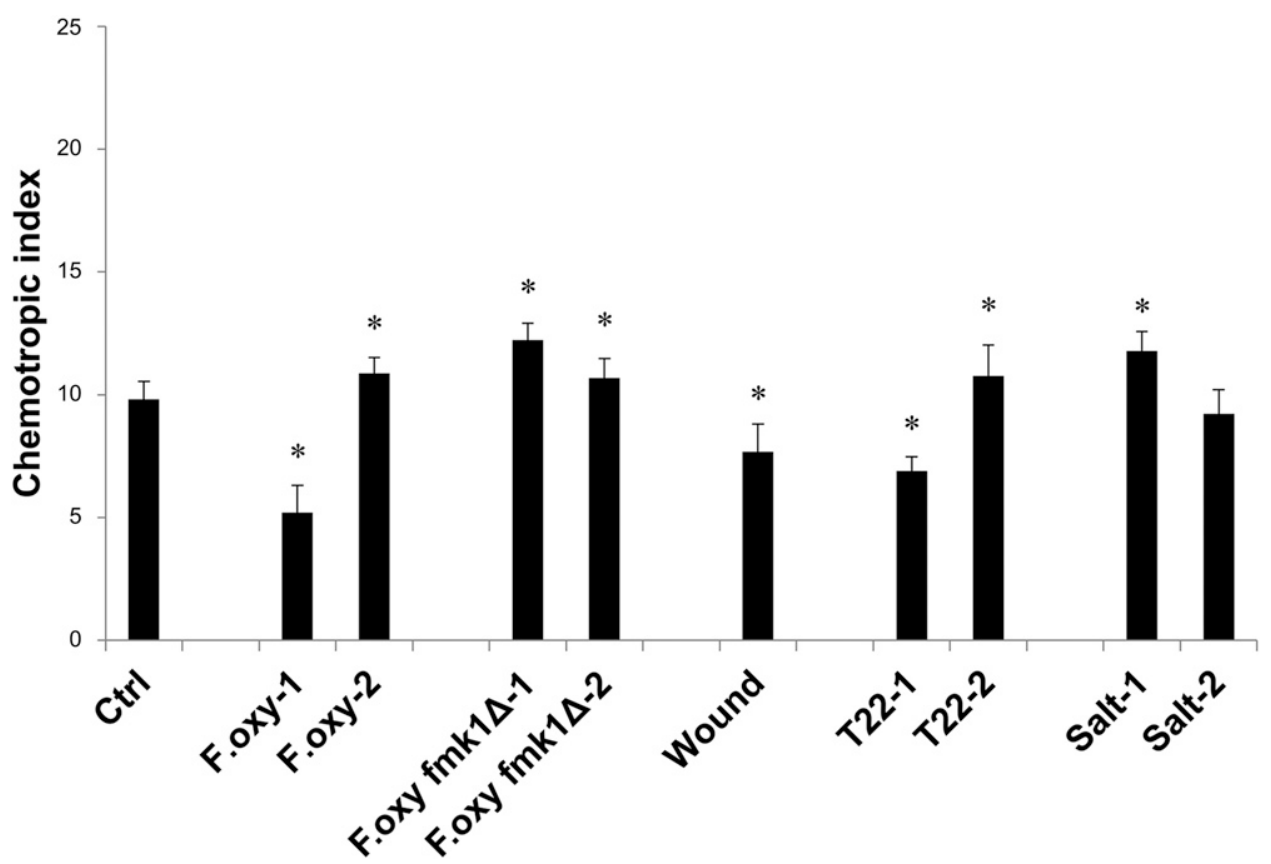

Fig. 6. Chemotropic activity of a $>3-\mathrm{kDa}$ fraction of tomato root exudates obtained by the split-root assay on Trichoderma harzianum germ tubes. The chemotropic index was calculated after $13 \mathrm{~h}$ of incubation at room temperature. Data are presented as the mean of three experiments. Error bars indicate standard deviation. An asterisk $(*)$ indicates values that are significantly different from the water control $(P<0.0001)$. 
directly exposed to the treatment (e.g., 12,13-epOME with a nonpathogenic $F$. oxysporum strain, salt, and T22), indicating the occurrence of a systemic response.

Our results demonstrate that oxylipins extracted from a $<3-\mathrm{kDa}$ fraction of tomato RE are involved in the chemotropic activity on Trichoderma germ tubes (Fig. 10). In particular, the chemotropic index in plants subjected to wounding, T22 (both T22-1 and T22-2), or saline stress (both salt-1 and salt-2) was doubled compared with the control (Fig. 10).

In most cases, an enhanced production of oxylipins in the samples corresponded to a positive chemoattraction of T. harzianum. In particular, wounding caused an increase both in chemoattraction

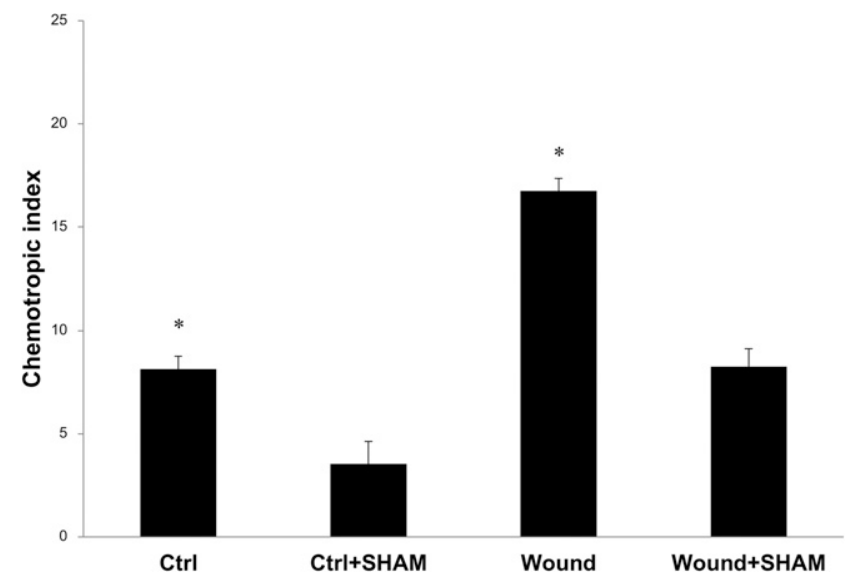

Fig. 8. Effect of the peroxidase inhibitor salicylhydroxamic acid (SHAM) on the chemotropic activity of tomato root exudates (RE), from the water control (Ctrl) or wounding (Wound) treatment, on Trichoderma harzianum germ tubes. Data are presented as the mean of three experiments. Error bars indicate standard deviation. An asterisk (*) indicates values that are significantly different between the untreated RE wounding and the treatment of RE + SHAM, $P<0.0001$. and in the production of almost all oxylipins found in the RE, followed by salt treatment, particularly on the side of the root not directly exposed to the condition. Also, in the case of roots placed in contact with germlings of $T$. harzianum T22, which produced an increased attraction of the same T22 strain, the level in five of eight different oxylipins was clearly enhanced. A similar result was obtained following the application of a nonpathogenic Fusarium mutant (F.oxy fmkl $1 \Delta-1$, F.oxy fmkl $1 \Delta-2$ ) to the tomato roots, in which the pattern of released oxylipins was similar to that of treatment with T22 (Table 2). By contrast, upon treatment with the pathogenic $F$. oxysporum wild-type strain, only two of 16 oxylipin samples (applied eight times, from the two sides of the split-root system) showed a significant increase compared with the control (Table 2). This may be related with the finding that plant oxylipins may reduce pathogen activity by affecting the synthesis of fungal oxylipins that regulate density-dependent growth (Horowitz Brown et al. 2008), virulence, and secondary metabolites production (Fischer and Keller 2016; Scala et al. 2014).

In this study, we also tested commercially available purified compounds as chemoattractants and we obtained the following results: i) the chemoattractant effect of RE was almost completely lost after boiling and the same result was obtained with the pure peroxidase and oxylipins; ii) treatment with SHAM, a peroxidase inhibitor, reduced the chemotropic index of the RE to about one-half of its value (Fig. 8); iii) the pure oxylipins (13-HODE and 9-HODE) found to be chemotropically active on T. harzianum were also detected in the collected RE and their concentration was significantly affected by the different stresses applied, with an increase for wounding and salt treatments that is coherent with the result from the chemotropic assay (Table 2; Fig. 3A), also, in terms of active concentration tested; iv) the clear dose-dependent response obtained in T. harzianum from testing the pure oxylipins (Fig. 11A) suggests a role of signaling factors for these compounds released by stressed tomato plants.

These data, together with those showing a differential effect of the various treatments on chemoattraction of T. harzianum

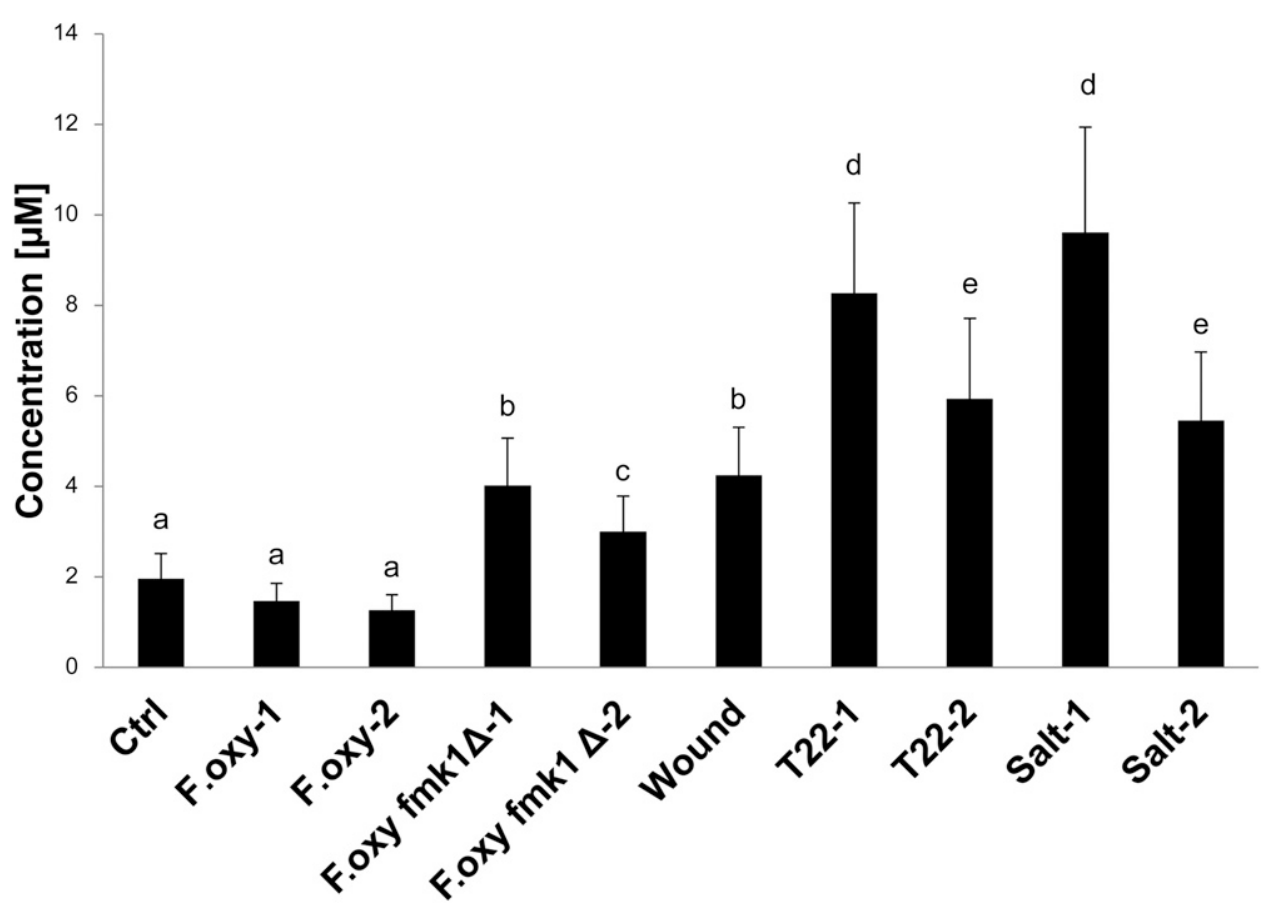

Fig. 9. Effect of different biotic or abiotic stress treatments on the concentration of oxylipins as detected by liquid chromatography and mass spectrometry analysis of tomato root exudates obtained from the split-root assay. Data values represent the means of three different replicates ( \pm standard deviation) that were analyzed by two-way analysis of variance; values with the same letter are not significantly different, as determined by least significant difference test at the $5 \%$ level of significance. 
versus that of pathogenic and nonpathogenic Fusarium oxysporum, indicates that roots are able to modulate the chemical attraction of soil microbes by selecting mutualistic fungi. More detailed studies on a variety of plant-microbe interactions are required to corroborate this hypothesis. In any case, our results indicate a polymorphism in the pattern of RE oxylipins that may be useful to understand how the systemic response to different stress conditions affects composition and activity of the rhizosphere-associated microbial population.

In summary, this work demonstrates that plants are able to activate a recruiting mechanism that enhances the attraction of biocontrol fungi such as $T$. harzianum $\mathrm{T} 22$ as part of a response to counteract biotic and abiotic stresses (Hermosa et al. 2012; Lorito et al. 2010). On the other hand, these root-colonizing microbes seem to have developed the ability to detect signals released by a stressed plant and direct their growth toward the host. Although the molecular mechanisms behind this process are unknown, our data suggest that peroxidases and oxylipins are involved in the process, because their production and release in REs is upregulated under stress and they can function as chemoattractants of Trichoderma spp. This information may be useful to better understand important biocontrol interactions and fine tune or improve the application of these fungi or of other "helper" microbes such as biopesticides and biofertilizers.

Table 2. Concentration of oxylipins in root exudates (RE) from the split-root system with tomato plants subjected to different treatments ${ }^{\mathrm{a}}$

\begin{tabular}{|c|c|c|c|c|c|c|c|c|}
\hline \multicolumn{9}{|c|}{ Oxylipin concentration $[\mu \mathrm{M}]$} \\
\hline Plant Treatment & 12,13 di HOME & 9,10 di HOME & 13-HODE & 9-HODE & 10-HODE & 9-oxoODE & 12,13-ерОМЕ & 9,10-ерОМЕ \\
\hline Water (Ctrl) & $0.0538 \pm 0.02 \mathrm{a}$ & $0.0405 \pm 0.01 \mathrm{a}$ & $0.2901 \pm 0.10 \mathrm{abc}$ & $0.1441 \pm 0.05 \mathrm{e}$ & $0.0566 \pm 0.02 \mathrm{c}$ & $0.0088 \pm 0.00 \mathrm{a}$ & $1.3371 \pm 0.36 \mathrm{c}$ & $0.0253 \pm 0.01 \mathrm{~b}$ \\
\hline Wounding & $0.2440 \pm 0.06 \mathrm{~d}$ & $0.1964 \pm 0.05 \mathrm{~d}$ & $0.4011 \pm 0.09 \mathrm{c}$ & $0.2645 \pm 0.07 \mathrm{~g}$ & $0.0903 \pm 0.02 \mathrm{~d}$ & $0.0118 \pm 0.00 \mathrm{a}$ & $2.9889 \pm 0.75 \mathrm{e}$ & $0.0548 \pm 0.01 \mathrm{c}$ \\
\hline \multicolumn{9}{|c|}{$\begin{array}{l}\text { Solution } 1 \text { (no } \\
\text { direct exposure) }\end{array}$} \\
\hline F.oxy-1 & $0.1275 \pm 0.03 b$ & $0.1723 \pm 0.05 \mathrm{c}$ & $0.0848 \pm 0.02 \mathrm{a}$ & $0.0556 \pm 0.02 \mathrm{bc}$ & $0.0043 \pm 0.00 \mathrm{a}$ & $0.0074 \pm 0.00 \mathrm{a}$ & $0.9914 \pm 0.26 b$ & $0.0291 \pm 0.01 \mathrm{~b}$ \\
\hline F.oxy $f m k 1 \Delta-1$ & $0.2292 \pm 0.06 \mathrm{~d}$ & $0.2030 \pm 0.06 \mathrm{~d}$ & $0.1395 \pm 0.03 \mathrm{ab}$ & $0.1023 \pm 0.03 \mathrm{~d}$ & $0.0334 \pm 0.01 \mathrm{~b}$ & $0.0141 \pm 0.00 \mathrm{a}$ & $3.2335 \pm 0.84 \mathrm{f}$ & $0.0633 \pm 0.02 \mathrm{~cd}$ \\
\hline Salt-1 & $0.2857 \pm 0.08 \mathrm{e}$ & $0.2708 \pm 0.06 \mathrm{e}$ & $0.2299 \pm 0.06 a b c$ & $0.1571 \pm 0.04 \mathrm{f}$ & $0.0932 \pm 0.02 \mathrm{~d}$ & $0.0117 \pm 0.00 \mathrm{a}$ & $8.3801 \pm 2.011$ & $0.1816 \pm 0.05 \mathrm{~g}$ \\
\hline $\mathrm{T} 22-1$ & $0.1812 \pm 0.04 \mathrm{c}$ & $0.1380 \pm 0.03 \mathrm{~b}$ & $0.1363 \pm 0.04 \mathrm{ab}$ & $0.0584 \pm 0.01 \mathrm{bc}$ & $0.0376 \pm 0.01 \mathrm{bc}$ & $0.0070 \pm 0.00 \mathrm{a}$ & $7.6015 \pm 1.82 \mathrm{i}$ & $0.1147 \pm 0.03 \mathrm{f}$ \\
\hline \multicolumn{9}{|c|}{$\begin{array}{l}\text { Solution } 2 \\
\quad \text { (direct exposure) }\end{array}$} \\
\hline F.oxy-2 & $0.0451 \pm 0.01 \mathrm{a}$ & $0.0447 \pm 0.01 \mathrm{a}$ & $0.1018 \pm 0.03 b c$ & $0.0534 \pm 0.01 \mathrm{~b}$ & $0.0307 \pm 0.01 \mathrm{~b}$ & $0.0124 \pm 0.00 \mathrm{a}$ & $0.9567 \pm 0.27 \mathrm{a}$ & $0.0143 \pm 0.00 \mathrm{a}$ \\
\hline F.oxy $f m k l \Delta-2$ & $0.2340 \pm 0.07 \mathrm{~d}$ & $0.1941 \pm 0.06 \mathrm{~d}$ & $0.1249 \pm 0.03 \mathrm{a}$ & $0.0658 \pm 0.02 \mathrm{c}$ & $0.0334 \pm 0.01 \mathrm{~b}$ & $0.0082 \pm 0.00 \mathrm{a}$ & $2.2886 \pm 0.57 \mathrm{~d}$ & $0.0564 \pm 0.02 \mathrm{~cd}$ \\
\hline Salt-2 & $0.5362 \pm 0.17 \mathrm{f}$ & $0.4726 \pm 0.14 \mathrm{e}$ & $0.0704 \pm 0.02 \mathrm{a}$ & $0.0453 \pm 0.01 \mathrm{~b}$ & $0.0340 \pm 0.01 b$ & $0.0042 \pm 0.00 \mathrm{a}$ & $4.2199 \pm 1.14 \mathrm{~g}$ & $0.0722 \pm 0.02 \mathrm{~d}$ \\
\hline $\mathrm{T} 22-2$ & $0.1853 \pm 0.06 \mathrm{c}$ & $0.1568 \pm 0.05 b$ & $0.1938 \pm 0.06 a b c$ & $0.0321 \pm 0.01 \mathrm{a}$ & $0.1124 \pm 0.03 \mathrm{e}$ & $0.0062 \pm 0.00 \mathrm{a}$ & $5.1494 \pm 1.54 \mathrm{~h}$ & $0.0930 \pm 0.03 \mathrm{e}$ \\
\hline
\end{tabular}

a RE were analyzed by liquid chromatography and mass spectrometry. The oxylipins tested were 12,13-dihydroxy-9Z-octadecenoic acid (12-13 di HOME); 9,10-dihydroxy-12Z-octadecenoic acid (9,10 di HOME); 13-hydroxy-9Z,11E-octadecadienoic acid (13-HODE); 9-hydroxy-10E,12Z-octadecadienoic acid (9-HODE); 10-hydroxy-8Z,12Z-octadecadienoic acid (10-HODE); 9-oxo-10E,12Z-octadecadienoic acid (9-oxoODE); 12,13 epoxy-9Z-octadecenoic acid (12,13-epOME); and 9,10-epoxy-12Z-octadecenoic acid (9,10-epOME). Data values are expressed as the means of three different replicates \pm standard deviation, analyzed by two-way analysis of variance. Values followed by the same letter within each column are not significantly different, as determined by least significant difference test at the $5 \%$ level of significance.

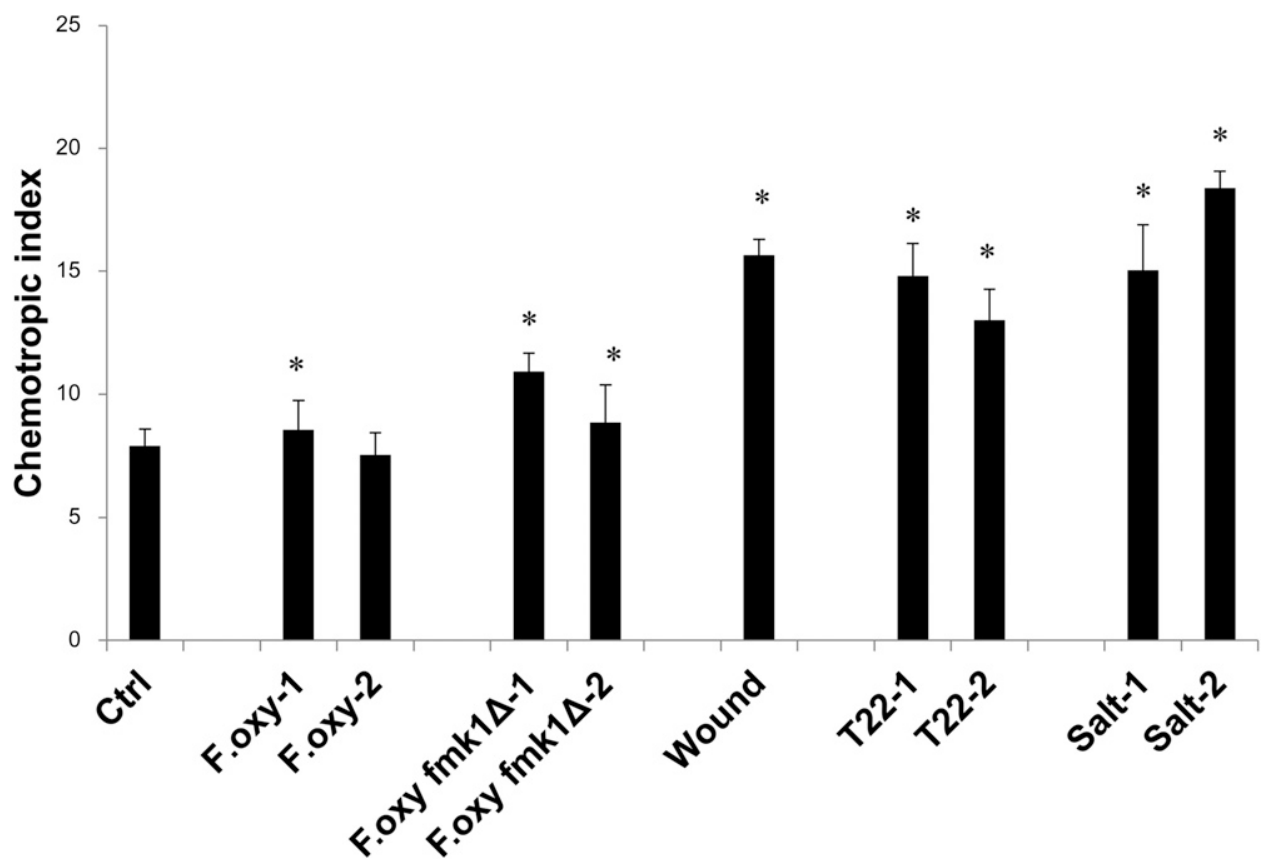

Fig. 10. Chemotropic activity of total oxylipins extracted from a $<3-\mathrm{kDa}$ fraction of tomato root exudates obtained by the split-root assay on Trichoderma harzianum germ tubes. The chemotropic index was calculated after $13 \mathrm{~h}$ of incubation at room temperature. Data are presented as the mean of three experiments. Error bars indicate standard deviation. An asterisk $\left(^{*}\right)$ indicates values that are significantly different from the water control $(P<0.0001)$ 


\section{MATERIALS AND METHODS}

\section{Fungal strains and culture conditions.}

Fungal cultures of Trichoderma harzianum T22 and Botrytis cinerea, from the collection of the Department of Agricultural Sciences of the University of Naples Federico II, were maintained at room temperature on potato dextrose agar (PDA) (High Media Pvt. Ltd) and on malt extract peptone (Sigma-Alcrich), respectively, and were subcultured bimonthly. Mature spores or mycelia were obtained from fresh PDA cultures and were used for the assays.

F. oxysporum f. sp. lycopersici 4287 was obtained from J. Tello, Universidad de Almería, Spain. A previously described

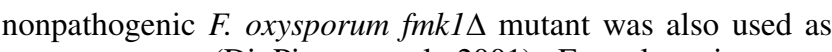
root treatment (Di Pietro et al. 2001). Fungal strains were routinely stored as microconidial suspensions at $-80^{\circ} \mathrm{C}$ in $30 \%$ (vol/vol) glycerol.

\section{In-vitro growth assays.}

Seeds of tomato (S. lycopersicum cvs. San Marzano 2 and Monica) or cucumber (Cucumis sativus cv. Marketmore) were surface-sterilized ( $1 \mathrm{~min}$ in $1 \%$ hypochlorite, then rinsed threetimes in distilled water), were transferred to 1 -liter sterile vials (Avamoplast) containing $50 \mathrm{ml}$ of Murashige and Skoog with vitamins (MS) (Sigma Aldrich) and 1\% agar (High Media Pvt.

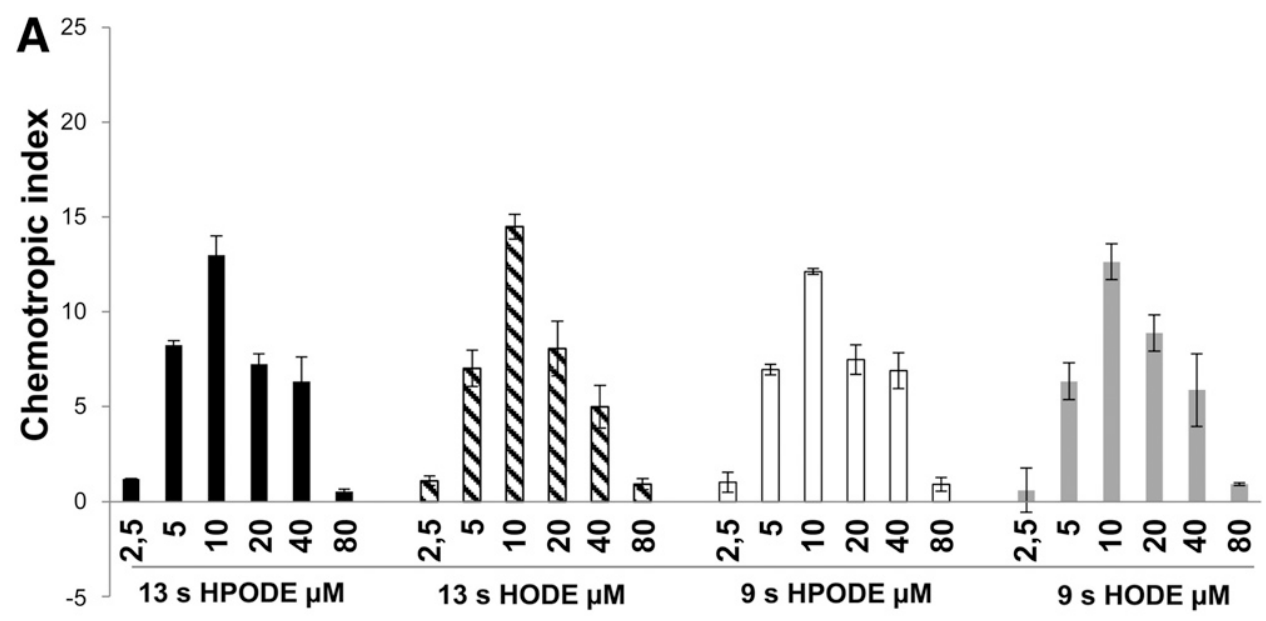

B

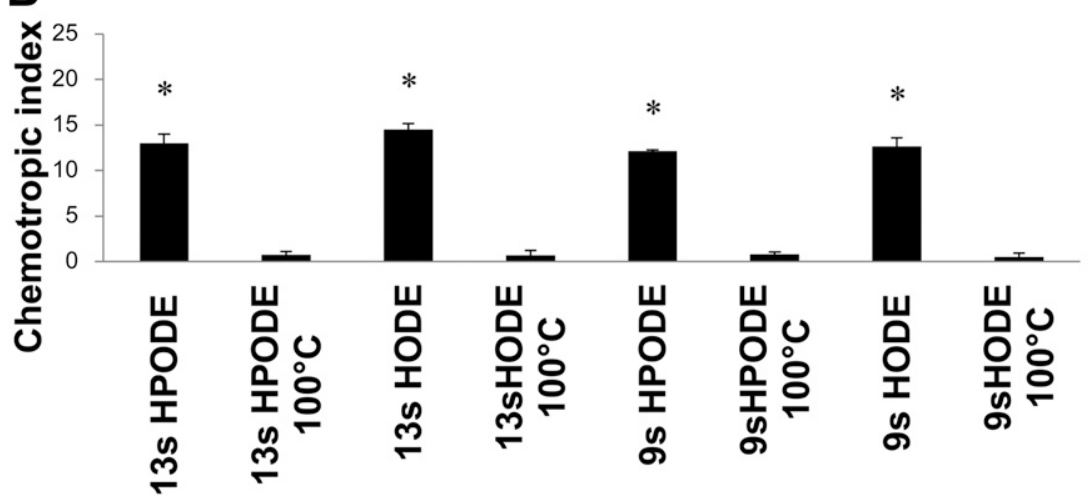

Fig. 11. A, Chemotropic activity of four commercial oxylipins on Trichoderma harzianum germ tubes used at different concentrations and $\mathbf{B}$, used at $10 \mu \mathrm{M}$ before and after boiling at $100^{\circ} \mathrm{C}$ for $22 \mathrm{~min}$. Tested compounds are 13S-HPODE $=13 \mathrm{~S}$-hydroperoxy-9Z,11E-octadecadienoic acid; 13 (S)-HODE $=13 \mathrm{~S}-$ hydroxy-9Z,11E-octadecadienoic acid; 9S-HPODE = 9S-hydroperoxy-10E,12Z-octadecadienoic acid; and 9(S)-HODE = 9S-hydroxy-10E,12Z-octadecadienoic acid. Data are presented as the mean of three experiments (versus the boiled oxylipins; $P<0.0001$ ). Bars indicate standard deviation. An asterisk $(*)$ indicates values that are significantly different between untreated and boiled oxylipins, $P<0.0001$.

Table 3. Treatments applied to tomato plants in a split-root system ${ }^{\mathrm{a}}$

\begin{tabular}{|c|c|c|c|}
\hline \multirow[b]{2}{*}{ Treatment } & \multicolumn{3}{|c|}{ Root extracts from the two sides of the split-root system } \\
\hline & $\begin{array}{l}\text { Indirectly exposed to treatment } \\
\text { (solution 1) }\end{array}$ & Solutions 1 and 2 combined & $\begin{array}{l}\text { Directly exposed to treatment } \\
\text { (solution 2) }\end{array}$ \\
\hline Water Control (Ctrl) & & Water & \\
\hline Pathogenic Fusarium oxysporum (F.oxy) & F.oxy -1 & & F.oxy -2 \\
\hline Nonpathogenic F. oxysporum (F.oxy fmkl) & F.oxy $f m k 1 \Delta-1$ & & F.oxy fmkl $1 \Delta-2$ \\
\hline $\begin{array}{l}\text { Biocontrol fungus Trichoderma harzianum } \\
\text { (T22) }\end{array}$ & $\mathrm{T} 22-1$ & & $\mathrm{~T} 22-2$ \\
\hline 100 mM NaCl (Salt) & Salt-1 & & Salt-2 \\
\hline Stem injury (Wound) & & Wounding & \\
\hline
\end{tabular}

\footnotetext{
a Treatments used to obtain root exudates (RE) from indirect (solution 1) and direct (solution 2) exposure to the tested factor and then used for chemotropism assays. Solutions 1 and 2 obtained from the two sides of the split root were pooled before testing for water control and for wounding but were kept and were assayed separately for the other treatments.
} 
Ltd), and were then left to germinate in the dark at room temperature. After emergence, plants were maintained under sterile conditions in a growth chamber $\left(28^{\circ} \mathrm{C}, 15\right.$-h light and $9-\mathrm{h}$ dark cycle) up to the second true leaf stage. Five leaflets were inoculated with $10 \mu \mathrm{l}$ of a Botrytis cinerea spore suspension (concentration $1 \times 10^{6}$ spores per milliliter) for a total of 10 point-inoculations per plant. Twelve hours after infection, $20 \mu \mathrm{l}$ of a T. harzianum T22 spore suspension (concentration $1 \times 10^{7}$ spores per milliliter) were applied to the surface of the MS substrate (Fig. 1A). The radius of the colony of the beneficial fungus mycelium was measured daily. Leaves of tomato plants inoculated with water were used as a control (Fig. 2). Ten plants were used for each condition and the experiment was repeated three times. Statistical analysis was conducted using analysis of variance least significant difference (LSD).

\section{Collection of tomato RE.}

Tomato (S. lycopersicum cv. San Marzano 2) seeds were surface-sterilized and germinated in sterile polystyrene boxes (5.5 $\mathrm{cm}$ hole diameter) containing moist vermiculite. Seedlings were grown for 45 days in a growth chamber at $28^{\circ} \mathrm{C}$ with a 15-h light and 9-h dark cycle. Tomato plants were gently uprooted from the vermiculite, and the roots were extensively rinsed with distilled water to remove the substrate. The root system of each plant was carefully split in two parts, both maintained in a 50-ml sterile water bath. One side remained in sterile water, while the other was exposed to the treatments (Fig. 1B; Table 3). The control condition consisted of leaving both root parts in water, without any treatment. A similar split-root method was used by Kassaw and Frugoli (2012) to study systemic signaling in the root system, with only one side subjected to a stress condition. In the present study, plants were treated with potential biotic and abiotic stress agents that were always applied only to one side of the split-root system, except for the wounding, which was inflicted to the stem. Five treatments were tested by exposing the roots to i) a virulent strain (strain 4287) of the vascular pathogen F. oxysporum f. sp. lycopersici (F.oxy, $1 \times 10^{6}$ spores per milliliter), ii) a nonpathogenic fmk $1 \Delta$ mutant of $F$. oxysporum (F.oxy $f m k 1 \Delta, 1 \times 10^{6}$ spores per milliliter), iii) the biological control agent $T$. harzianum T22 $\left(1 \times 10^{6}\right.$ spores per milliliter $)$, iv) a salt stress (100 $\mathrm{mM} \mathrm{NaCl}$ in water), and v) a wounding made by excision of the shoot apex (Table 3). Plants were maintained at room temperature for $48 \mathrm{~h}$. Three replicates were used for each condition.

The resulting REs were collected from each side of the splitroot system maintained in sterile conditions, were filtered through a $0.22-\mu \mathrm{m}$ Millipore membrane, were concentrated 10times by lyophilization, and then, were stored at $-20^{\circ} \mathrm{C}$ until use. The excess $\mathrm{NaCl}$ in $\mathrm{RE}$ from the Salt-2 treatment (Table 3) was removed by using a filter unit (Amicon Ultra 0.5 centrifugal filter 3-kDa Ultracel 3K membrane, Millipore, Merck). The samples obtained from the tubes hosting the root side never directly exposed to the treatment was named solution 1 , while the other, which was placed directly in contact with the stress agent tested, was named solution 2. The REs from the two solutions were always maintained and assayed separately, except for water control and wounding, in which the solutions 1 and 2 were combined before testing (Table 3 ).

\section{Chemotropism assays.}

The chemotropism assay was based on the protocol of Turrà et al. (2015) with some modifications. Briefly, spores of $T$. harzianum T22 or F. oxysporum f. sp. lycopersici were incorporated in a 4-ml water agar medium (WA) $(0.5 \% \mathrm{wt} / \mathrm{vol})$ (Oxoid, Thermo Fisher Scientific) at a final concentration of $1 \times 10^{6}$ spores per milliliter, and the spore-containing substrate was poured into a petri dish. Once solidified, two parallel grooves were produced on the surface of the WA as shown in Figure 1C. One of the grooves was filled with $40 \mu \mathrm{l}$ of the chemoattractant solution and the other with the relative solvent at the concentration used in the assay (control). Plates were maintained in a closed plastic box at $28^{\circ} \mathrm{C}$ in the dark and the chemotropic response was evaluated after $13 \mathrm{~h}$.

The chemotropism assay was conducted testing the activity of the RE solutions described in Table 3. RE solutions demonstrating the highest chemotropic effect on Trichoderma or Fusarium germ tubes were also tested after a heat treatment $\left(100^{\circ} \mathrm{C}\right.$ for $\left.22 \mathrm{~min}\right)$.

Chemotropic effect of RE on T. harzianum and $F$. oxysporum germ-tube development was determined as described by Turrà et al. (2015), using an Olympus binocular microscope (200x magnification) to observe the number of hyphal tips growing toward the test compound in comparison with those growing toward the solvent control (Turrà et al. 2015). For each tested compound, the mean of 500 spores randomly scored was calculated. Data used for statistical analysis were the means from three independent experiments. Statistical analysis was conducted using a Student's $t$ test. A chemotropic index value was attributed to each sample. It was calculated as $\left[\left(\mathrm{H}_{\text {test }}-\mathrm{H}_{\text {solv }}\right) / \mathrm{H}_{\text {total }}\right.$ $\times 100$ ], whereby $\mathrm{H}_{\text {test }}$ is the number of hyphae growing toward the tested compound, $\mathrm{H}_{\text {solv }}$ is the number of hyphae growing toward the solvent control, and $\mathrm{H}_{\text {total }}$ is the total number of hyphae counted.

The same experimental settings were used to analyze the chemotropic activity of RE fractions containing peroxidases and oxylipins as well as of their commercial purified analogs. HRP type VI (Sigma Aldrich) was used at two concentrations (4 and $256 \mu \mathrm{M})$ in water. Commercial oxylipins (OXY) (Cayman Chemicals) 9S-HPODE, 13S-hydroperoxy9Z,11E-octadecadienoicacid (13S-HPODE), 9S-hydroxy-10E, 12Z-octadecadienoic acid [9(S)-HODE], and 13S-hydroxy9Z,11E-octadecadienoic acid [13(S)-HODE] were used at 2.5, $5,10,20,40$, and $80 \mu \mathrm{M}$ in ethanol. The appropriate solvent controls were included in the assays. Heat stability of HRP and OXY effect was tested as described above. Finally, the peroxidase inhibitor SHAM (Sigma Aldrich) was added to the selected REs at a final concentration of $60 \mathrm{mM}$, to inhibit the chemotropism effect on hyphal growth eventually caused by peroxidase activity.

\section{Peroxidase activity assay.}

Evaluation of peroxidase activity in RE was carried out in 96-well microtiter plates according to the method described by Turrà et al. (2015). The reaction mixture contained $0.91 \mathrm{mM}$ ABTS (2,2'-Azino-bis(3-ethylbenzthiazoline-6-sulfonic acid) (Sigma-Aldrich), $2.5 \mathrm{mM} \mathrm{H} \mathrm{H}_{2} \mathrm{O}_{2}$ in phosphate-citrate buffer (51 $\mathrm{mM} \mathrm{Na}_{2} \mathrm{HPO}_{4}, 24 \mathrm{mM}$ citric acid, $\mathrm{pH}$ 5.6) in a final volume of $150 \mu$ l. For each reaction, a blank containing heat-inactivated (20-min boil) peroxidase was included. Reactions were incubated at $28^{\circ} \mathrm{C}$ and absorbance at $405 \mathrm{~nm}\left(\mathrm{~A}_{405} \mathrm{~nm}\right)$ was measured at different time intervals $\left(\Delta \mathrm{A}_{405} \mathrm{~nm}\right)$, using a Spectrafluor Plus microplate reader (Tecan). Peroxidase activity was calculated as units per milliliter, using the formula: $\left[\left(\Delta \mathrm{A}_{405 \mathrm{~nm}} / \mathrm{min}\right.\right.$ test $-\Delta \mathrm{A}_{405 \mathrm{~nm}} /$ min blank $) \times$ (final volume of reaction in $\mathrm{ml}) \times$ (dilution factor of enzyme)]/ [(millimolar extinction coefficient of oxidized ABTS at $405 \mathrm{~nm}) \times$ (volume enzyme used in $\mathrm{ml}$ )]. Statistical analysis was conducted using the LSD test at 5\% level of significance.

\section{Characterization of root-secreted oxylipins.}

A modified protocol of Ludovici et al. (2014) was used for testing the presence of oxylipins in tomato RE and discriminating among different forms of these compounds. Commercially available OXY solutions (Cayman Chemicals) were used as standards for a LC/MS-based analysis of the RE samples. 
Known oxylipins included 12-13 di HOME (12,13-dihydroxy-9Zoctadecenoic acid), 9,10 di HOME (9,10-dihydroxy-12Zoctadecenoic acid), 13-HODE (13-hydroxy-9Z,11E-octadecadienoic acid), 9-HODE (9-hydroxy-10E,12Z-octadecadienoic acid), 10-HODE (10-hydroxy-8Z,12Z-octadecadienoic acid), 9-OxoODE (9-oxo-10E,12Z-octadecadienoic acid), 12,13-EpOME (12,13 epoxy-9Z-octadecenoic acid), and 9,10-EpOME (9,10-epoxy12Z-octadecenoic acid). LC (HPLC 1200 series rapid resolution) coupled to a triple quadrupole mass spectrometer (G6410A series triple quadrupole, QqQ; Agilent Technologies) equipped with an electrospray ionization source was used. The acquisition was in negative-ion mode. Chromatographic separations were performed with a Zorbax ECLIPSE XDB-C18 rapid resolution HT $4.6 \times 50 \mathrm{~mm} 1.8 \mu \mathrm{m}$ p.s. column (Agilent Technologies). Methanol (MeOH), acetonitrile, hexane (Hex) isopropyl alcohol (iPrOH), and formic acid were of LC/MS grade (Merck, Fluka). The internal reference standard added for the quantitative analysis was the deuterated 9 hydroxy-10E,12Z-octadecadienoic acid (9HODEd4, molecular weight $300.5 \mathrm{~g} \mathrm{~mol}^{-1}$ ), at a final concentration of $2 \mu \mathrm{M}$. The RE from the various split-root treatments were resuspended in $400 \mu \mathrm{l}$ of sterile water and were mixed with $1.2 \mathrm{ml}$ of extraction mixture $(\mathrm{Hex} / \mathrm{PrOH}, 3: 2$, vol/vol, with $0.0025 \% \mathrm{wt} / \mathrm{vol}$ of butylated hydroxytoluene). The organic phase was collected and dried under $\mathrm{N}_{2}$, was solubilized in $100 \mu \mathrm{l}$ of $\mathrm{MeOH}$, and was analyzed. Experiments in multiple reaction monitoring (MRM) of the parent ions $[\mathrm{M}-\mathrm{H}]^{-}$of each target compound were performed to quantify specific oxylipins into RE samples (Ludovici et al. 2014). MRM data were processed using Mass Hunter Quantitative software (B.03.02 version, Agilent Technologies).

The concentration of each oxylipin in the final volume of $100 \mu \mathrm{l}$ was reported as micromoles. Results of the oxylipin quantification from different matrices were given as the mean ( \pm standard error) of six replicates from two independent experiments. All data were statistically evaluated with GraphPad Prism 5.0 (GraphPad Software, Inc.). Means were compared by a Mann-Whitney test.

\section{Isolation of peroxidase- and oxylipin-containing fractions from RE.}

Aliquots $(2 \mathrm{ml})$ of RE from each treatment were sizefractionated using 3-kDa filter units (Amicon Ultracel 3K membrane, Millipore, Merck) in order to separate peroxidases from oxylipins on the basis of their molecular weights. The fraction containing oxylipins $(400 \mu \mathrm{l})$ was then extracted with $1.2 \mathrm{ml}$ of a Hex and isopropanol mixture (Hex/iPrOH, 3:2, vol/vol) and the organic phase was collected, was dried under $\mathrm{N}_{2}$, and was redissolved in $100 \mu \mathrm{l}$ of ethanol. The obtained fractions containing, separately, peroxidases and oxylipins were used in chemotropic assays with Trichoderma spores as described above.

\section{LITERATURE CITED}

Akiyama, K., Matsuzaki, K., and Hayashi, H. 2005. Plant sesquiterpenes induce hyphal branching in arbuscular mycorrhizal fungi. Nature 435: 824-827.

Altomare, C., Norvell, W. A., Björkman, T., and Harman, G. E. 1999. Solubilization of phosphates and micronutrients by the plant-growthpromoting and biocontrol fungus Trichoderma harzianum Rifai 1295-22. Appl. Environ. Microbiol. 65:2926-2933.

Badri, D. V., Weir, T. L., van der Lelie, D., and Vivanco, J. M. 2009. Rhizosphere chemical dialogues: Plant-microbe interactions. Curr. Opin. Biotechnol. 20:642-650.

Bais, H. P., Walker, T. S., Schweizer, H. P., and Vivanco, J. M. 2002. Root specific elicitation and antimicrobial activity of rosmarinic acid in hairy root cultures of Ocimum basilicum. Plant Physiol. Biochem. 40:983-995.

Bais, H. P., Weir, T. L., Perry, L. G., Gilroy, S., and Vivanco, J. M. 2006. The role of root exudates in rhizosphere interactions with plants and other organisms. Annu. Rev. Plant Biol. 57:233-266.
Battaglia, D., Bossi, S., Cascone, P., Digilio, M. C., Prieto, J. D., Fanti, P., Guerrieri, E., Iodice, L., Lingua, G., Lorito, M., Maffei, M. E., Massa, N., Ruocco, M., Sasso, R., and Trotta, V. 2013. Tomato below groundabove ground interactions: Trichoderma longibrachiatum affects the performance of Macrosiphum euphorbiae and its natural antagonists. Mol. Plant-Microbe Interact. 26:1249-1256.

Berendsen, R. L., Pieterse, C. M., and Bakker, P. A. 2012. The rhizosphere microbiome and plant health. Trends Plant Sci. 17:478-486.

Berg, G., Grube, M., Schloter, M., and Smalla, K. 2014. Unraveling the plant microbiome: Looking back and future perspectives. Front. Microbiol. 5:148.

Bertin, C., Yang, X., and Weston, L. A. 2003. The role of root exudates and allelochemicals in the rhizosphere. Plant Soil 256:67-83.

Besserer, A., Puech-Pagès, V., Kiefer, P., Gomez-Roldan, V., Jauneau, A., Roy, S., Portais, J. C., Roux, C., Bécard, G., and Séjalon-Delmas, N. 2006. Strigolactones stimulate arbuscular mycorrhizal fungi by activating mitochondria. PLoS Biol. 4:e226.

Bezemer, T. M., and van Dam, N. M. 2005. Linking aboveground and belowground interactions via induced plant defenses. Trends Ecol. Evol. Amst. 20:617-624.

Blée, E. 2002. Impact of phyto-oxylipins in plant defense. Trends Plant Sci. 7:315-322.

Bressan, M., Roncato, M. A., Bellvert, F., Comte, G., Haichar, F. Z., Achouak, W., and Berge, O. 2009. Exogenous glucosinolate produced by Arabidopsis thaliana has an impact on microbes in the rhizosphere and plant roots. ISME J. 3:1243-1257.

Buee, M., Rossignol, M., Jauneau, A., Ranjeva, R., and Bécard, G. 2000. The pre-symbiotic growth of arbuscular mycorrhizal fungi is induced by a branching factor partially purified from plant root exudates. Mol. Plant-Microbe Interact. 13:693-698.

Cameron, J. N., and Carlile, M. J. 1981. Binding of isovaleraldehyde, an attractant, to zoospores of the fungus Phytophthora palmivora in relation to zoospore chemotaxis. J. Cell Sci. 49:273-281.

de Santiago, A., Quintero, J. M., Avilés, M., and Delgado, A. 2011. Effect of Trichoderma asperellum strain T34 on iron, copper, manganese, and zinc uptake by wheat grown on a calcareous medium. Plant Soil 342:97-104.

DeCoste, N. J., Gadkar, V. J., and Filion, M. 2010. Verticillium dahliae alters Pseudomonas spp. populations and HCN gene expression in the rhizosphere of strawberry. Can. J. Microbiol. 56:906-915.

Di Pietro, A., García-MacEira, F. I., Méglecz, E., and Roncero, M. I. G. 2001. A MAP kinase of the vascular wilt fungus Fusarium oxysporum is essential for root penetration and pathogenesis. Mol. Microbiol. 39:1140-1152.

Doornbos, R. F., van Loon, L. C., and Bakker, P. A. 2012. Impact of root exudates and plant defense signaling on bacterial communities in the rhizosphere. A review. Agron. Sustain. Dev. 32:227-243.

Haichar, F. Z., Marol, C., Berge, O., Rangel-Castro, J. I., Prosser, J. I., Balesdent, J., Heulin, T., and Achouak, W. 2008. Plant host habitat and root exudates shape soil bacterial community structure. ISME J. 2:1221-1230.

Feussner, I., and Wasternack, C. 2002. The lipoxygenase pathway. Annu. Rev. Plant Biol. 53:275-297.

Fischer, G. J., and Keller, N. P. 2016. Production of cross-kingdom oxylipins by pathogenic fungi: An update on their role in development and pathogenicity. J. Microbiol. 54:254-264.

Fons, F., Amellal, N., Leyval, C., Saint-Martin, N., and Henry, M. 2003. Effects of Gypsophila saponins on bacterial growth kinetics and on selection of subterranean clover rhizosphere bacteria. Can. J. Microbiol. 49:367-373.

Halitschke, R., Stenberg, J. A., Kessler, D., Kessler, A., and Baldwin, I. T. 2008. Shared signals-'Alarm calls' from plants increase apparency to herbivores and their enemies in nature. Ecol. Lett. 11:24-34.

Harman, G. E., Howell, C. R., Viterbo, A., Chet, I., and Lorito, M. 2004. Trichoderma species-Opportunistic, avirulent plant symbionts. Nat. Rev. Microbiol. 2:43-56.

Hermosa, R., Rubio, M. B., Cardoza, R. E., Nicolás, C., Monte, E., and Gutiérrez, S. 2013. The contribution of Trichoderma to balancing the costs of plant growth and defense. Int. Microbiol. 16:69-80.

Hermosa, R., Viterbo, A., Chet, I., and Monte, E. 2012. Plant-beneficial effects of Trichoderma and of its genes. Microbiology 158:17-25.

Horowitz Brown, S., Zarnowski, R., Sharpee, W. C., and Keller, N. P. 2008. Morphological transitions governed by density dependence and lipoxygenase activity in Aspergillus flavus. Appl. Environ. Microbiol. 74:5674-5685.

Howe, G. A., and Schilmiller, A. L. 2002. Oxylipin metabolism in response to stress. Curr. Opin. Plant Biol. 5:230-236.

Inceoğlu, Ö., Al-Soud, W. A., Salles, J. F., Semenov, A. V., and van Elsas, J. D. 2011. Comparative analysis of bacterial communities in a potato field as determined by pyrosequencing. PLoS One 6:e23321.

Inceoğlu, O., Salles, J. F., van Overbeek, L., and van Elsas, J. D. 2010 Effects of plant genotype and growth stage on the betaproteobacterial communities associated with different potato cultivars in two fields Appl. Environ. Microbiol. 76:3675-3684. 
Jousset, A., Rochat, L., Lanoue, A., Bonkowski, M., Keel, C., and Scheu, S. 2011. Plants respond to pathogen infection by enhancing the antifungal gene expression of root-associated bacteria. Mol. Plant-Microbe Interact. 24:352-358.

Kamilova, F., Kravchenko, L. V., Shaposhnikov, A. I., Azarova, T., Makarova, N., and Lugtenberg, B. 2006a. Organic acids, sugars, and L-tryptophane in exudates of vegetables growing on stonewool and their effects on activities of rhizosphere bacteria. Mol. Plant-Microbe Interact. 19:250-256.

Kamilova, F., Kravchenko, L. V., Shaposhnikov, A. I., Makarova, N., and Lugtenberg, B. 2006b. Effects of the tomato pathogen Fusarium oxysporum f. sp. radicis-lycopersici and of the biocontrol bacterium Pseudomonas fluorescens WCS365 on the composition of organic acids and sugars in tomato root exudate. Mol. Plant-Microbe Interact. 19:1121-1126.

Kassaw, T. K., and Frugoli, J. A. 2012. Simple and efficient methods to generate split roots and grafted plants useful for long-distance signaling studies in Medicago truncatula and other small plants. Plant Methods 8:38.

Kessler, A., and Baldwin, I. T. 2001. Defensive function of herbivoreinduced plant volatile emissions in nature. Science 291:2141-2144.

Koske, R. E. 1982. Evidence for a volatile attractant from plant roots affecting germ tubes of a VA mycorrhizal fungus. Trans. Br. Mycol. Soc. 79:305-310.

Lace, B., Genre, A., Woo, S., Faccio, A., Lorito, M., and Bonfante, P. 2015. Gate crashing arbuscular mycorrhizas: In vivo imaging shows the extensive colonization of both symbionts by Trichoderma atroviride. Environ. Microbiol. Rep. 7:64-77.

Lanoue, A., Burlat, V., Henkes, G. J., Koch, I., Schurr, U., and Röse, U. S. 2010. De novo biosynthesis of defense root exudates in response to Fusarium attack in barley. New Phytol. 185:577-588.

Lebeis, S. L. 2014. The potential for give and take in plant-microbiome relationships. Front. Plant Sci. 5:287.

Lee, B., Lee, S., and Ryu, C. M. 2012. Foliar aphid feeding recruits rhizosphere bacteria and primes plant immunity against pathogenic and non-pathogenic bacteria in pepper. Ann. Bot. 110:281-290.

Lorito, M., Woo, S. L., Harman, G. E., and Monte, E. 2010. Translational research on Trichoderma: From 'omics to the field. Annu. Rev. Phytopathol. 48:395-417.

Ludovici, M., Ialongo, C., Reverberi, M., Beccaccioli, M., Scarpari, M., and Scala, V. 2014. Quantitative profiling of oxylipins through comprehensive LC-MS/MS analysis of Fusarium verticillioides and maize kernels. Food Addit. Contam. Part A Chem. Anal. Control Expo. Risk Assess. 31: 2026-2033.

Mark, G. L., Dow, J. M., Kiely, P. D., Higgins, H., Haynes, J., Baysse, C., Abbas, A., Foley, T., Franks, A., Morrissey, J., and O'Gara, F. 2005. Transcriptome profiling of bacterial responses to root exudates identifies genes involved in microbe-plant interactions. Proc. Natl. Acad. Sci. U.S.A. 102:17454-17459.

Marra, R., Ambrosino, P., Carbone, V., Vinale, F., Woo, S. L., Ruocco, M., Ciliento, R., Lanzuise, S., Ferraioli, S., Soriente, I., Gigante, S., Turrà, D., Fogliano, V., Scala, F., and Lorito, M. 2006. Study of the three-way interaction between Trichoderma atroviride, plant and fungal pathogens by using a proteomic approach. Curr. Genet. 50:307-321.

Massee, G. 1905. On the origin of parasitism in fungi. Philos. Trans. R. Soc. Lond., B Contain. Pap. Biol. Character 197:7-24.

Matsui, K. 2006. Green leaf volatiles: Hydroperoxide lyase pathway of oxylipin metabolism. Curr. Opin. Plant Biol. 9:274-280.

Mavrodi, O. V., Mavrodi, D. V., Parejko, J. A., Thomashow, L. S., and Weller, D. M. 2012. Irrigation differentially impacts populations of indigenous antibiotic-producing Pseudomonas spp. in the rhizosphere of wheat. Appl. Environ. Microbiol. 78:3214-3220.

Micallef, S. A., Shiaris, M. P., and Colón-Carmona, A. 2009. Influence of Arabidopsis thaliana accessions on rhizobacterial communities and natural variation in root exudates. J. Exp. Bot. 60:1729-1742.

Morris, P. F., Bone, E., and Tyler, B. M. 1998. Chemotropic and contact responses of Phytophthora sojae hyphae to soybean isoflavonoids and artificial substrates. Plant Physiol. 117:1171-1178.

Neal, A. L., and Ton, J. 2013. Systemic defense priming by Pseudomonas putida KT2440 in maize depends on benzoxazinoid exudation from the roots. Plant Signal. Behav. 8:e22655.

Oger, P. M., Mansouri, H., Nesme, X., and Dessaux, Y. 2004. Engineering root exudation of Lotus toward the production of two novel carbon compounds leads to the selection of distinct microbial populations in the rhizosphere. Microb. Ecol. 47:96-103.
Passardi, F., Penel, C., and Dunand, C. 2004. Performing the paradoxical: How plant peroxidases modify the cell wall. Trends Plant Sci. 9:534-540.

Paterson, E., Sim, A., Standing, D., Dorward, M., and McDonald, A. J. S. 2006. Root exudation from Hordeum vulgare in response to localized nitrate supply. J. Exp. Bot. 57:2413-2420.

Prost, I., Dhondt, S., Rothe, G., Vicente, J., Rodriguez, M. J., Kift, N., Carbonne, F., Griffiths, G., Esquerré-Tugayé, M.-T., Rosahl, S., Castresana, C., Hamberg, M., and Fournier, J. 2005. Evaluation of the antimicrobial activities of plant oxylipins supports their involvement in defense against pathogens. Plant Physiol. 139:1902-1913.

Raaijmakers, J. M. 2015. The minimal rhizosphere microbiome. Pages 411-417 in: Principles of Plant-Microbe Interactions. Springer International Publishing, Cham, Switzerland.

Rudrappa, T., Czymmek, K. J., Paré, P. W., and Bais, H. P. 2008. Rootsecreted malic acid recruits beneficial soil bacteria. Plant Physiol. 148: 1547-1556.

Santino, A., Bonsegna, S., Domenico, S. D., and Poltronieri, P. 2010. Plant oxylipins and their contribution to plant defence. Curr. Top. Plant Biol. 11:103-111.

Scala, V., Giorni, P., Cirlini, M., Ludovici, M., Visentin, I., Cardinale, F., Fabbri, A. A., Fanelli, C., Reverberi, M., Battilani, P., Galaverna, G., and Dall'Asta, C. 2014. LDS1-produced oxylipins are negative regulators of growth, conidiation and fumonisin synthesis in the fungal maize pathogen Fusarium verticillioides. Front. Microbiol. 5:669.

Shoresh, M., Harman, G. E., and Mastouri, F. 2010. Induced systemic resistance and plant responses to fungal biocontrol agents. Annu. Rev. Phytopathol. 48:21-43.

Siebers, M., Brands, M., Wewer, V., Duan, Y., Hölzl, G., and Dörmann, P. 2016. Lipids in plant-microbe interactions. Mol. Cell Biol. Lipids 1861: 1379-1395.

Thijs, S., Sillen, W., Rineau, F., Weyens, N., and Vangronsveld, J. 2016. Towards an enhanced understanding of plant-microbiome interactions to improve phytoremediation: engineering the metaorganism. Front. Microbiol. 7:341.

Trivedi, P., Trivedi, C., Grinyer, J., Anderson, I. C., and Singh, B. K. 2016. Harnessing host-vector microbiome for sustainable plant disease management of phloem-limited bacteria. Front. Plant Sci. 7:1423.

Turrà, D., El Ghalid, M., Rossi, F., and Di Pietro, A. 2015. Fungal pathogen uses sex pheromone receptor for chemotropic sensing of host plant signals. Nature 527:521-524.

Vinale, F., Sivasithamparam, K., Ghisalberti, E. L., Marra, R., Barbetti, M. J., Li, H., Woo, S. L., and Lorito, M. 2008a. A novel role for Trichoderma secondary metabolites in the interactions with plants. Physiol. Mol. Plant Pathol. 72:80-86.

Vinale, F., Sivasithamparam, K., Ghisalberti, E. L., Marra, R., Woo, S. L., and Lorito, M. 2008b. Trichoderma-plant-pathogen interactions. Soil Biol. Biochem. 40:1-10.

Weichert, H., Stenzel, I., Berndt, E., Wasternack, C., and Feussner, I. 1999. Metabolic profiling of oxylipins upon salicylate treatment in barley leaves-Preferential induction of the reductase pathway by salicylate(1). FEBS Lett. 464:133-137.

Weinert, N., Meincke, R., Gottwald, C., Heuer, H., Gomes, N. C., Schloter, M., Berg, G., and Smalla, K. 2009. Rhizosphere communities of genetically modified zeaxanthin-accumulating potato plants and their parent cultivar differ less than those of different potato cultivars. Appl. Environ. Microbiol. 75:3859-3865.

Woo, S. L., Ruocco, M., Vinale, F., Nigro, M., Marra, R., Lombardi, N., Pascale, A., Lanzuise, S., Manganiello, G., and Lorito, M. 2014. Trichodermabased products and their widespread use in agriculture. Open Mycol. J. 8:71-126.

Woo, S. L., Scala, F., Ruocco, M., and Lorito, M. 2006. The molecular biology of the interactions between Trichoderma spp., phytopathogenic fungi, and plants. Phytopathology 96:181-185.

Yang, J. W., Yi, H. S., Kim, H., Lee, B., Lee, S., Ghim, S. Y., and Ryu, C. M. 2011. Whitefly infestation of pepper plants elicits defence responses against bacterial pathogens in leaves and roots and changes the belowground microflora. J. Ecol. 99:46-56.

Zhang, Y., Du, B. H., Jin, Z. G., Li, Z. H., Song, H. N., and Ding, Y. Q. 2011. Analysis of bacterial communities in rhizosphere soil of healthy and diseased cotton (Gossypium sp.) at different plant growth stages. Plant Soil 339:447-455. 